\title{
On the influence of individual characteristics and personality traits on the user experience with multi-sensorial media: an experimental insight
}

\author{
Iris Galloso • Juan F. Palacios • Claudio Feijóo • Asunción Santamaría
}

\begin{abstract}
Recent studies encourage the development of sensorially-enriched media to enhance the user experience by stimulating senses other than sight and hearing. Sensory effects as odor, wind, vibration and light effects, as well as an enhanced audio quality, have been found to favour media enjoyment and to have a positive influence on the sense of Presence and on the perceived quality, relevance and reality of a multimedia experience. In particular, sports is among the genres that could benefit the most from these solutions. Several works have demonstrated also the technical feasibility of implementing and deploying end-to-end solutions integrating sensory effects into a legacy system. Thus, multi-sensorial media emerges as a mean to deliver a new form of immersive experiences to the mass market in a non-disruptive manner. However, many questions remain concerning issues as the sensory effects that can better complement a given audiovisual content or the best way in which to integrate and combine them to enhance the user experience of a target audience segment. The work presented in this paper aims to gain insight into the impact of binaural audio and sensory (light and olfactory) effects on the sports media experience, both at the overall level (average effect) and as a function of users' characteristics (heterogeneous effects). To this aim, we conducted an experimental study exploring the influence of these immersive elements on the quality and Presence dimensions of the media experience. Along the quality dimension, we look for possible variations on the quality scores assigned to the overall media experience and
\end{abstract}


to the media components content, image, audio and sensory effects. The potential impact on Presence is analyzed in terms of Spatial Presence and Engagement. The users' characteristics considered encompass specific personal affective, cognitive and behavioral attributes. At the overall level we found that participants preferred binaural audio over standard stereo audio and that the presence of sensory effects increased significantly the level of Spatial Presence. Several heterogeneous effects were also revealed as a result of our experimental manipulations. Whereas binaural audio was found to have a generalized impact on the majority of the quality and Presence measures considered, the effects of sensory effects concentrate mainly on the Presence dimension. Personal characteristics explained most of the variation in the dependent variables, being individuals' preferences in relation to the content, knowledge of involved technologies, tendency to emotional involvement and conscientiousness among the user variables with the most generalized influence. In particular, the former two features seem to present a conflict in the allocation of attentional resources towards the media content versus the technical features of the system, respectively. Additionally, football fans' experience seems to be modulated by emotional processes whereas for not fans cognitive processes -and in particular those related to quality judgment- prevail.

\section{Introduction}

The concepts of Presence -related to the subjective sense of "physical transportation"- and of Quality of Experience (QoE) - associated to quality perception- are at the core of the two major approaches analyzing the psycho-physiological mechanisms that underline user experience with media. Although these concepts proceed from different contexts and research communities, recent studies not only demonstrate their general validity but also suggest fundamental interactions between their constructs (see [24] and citations therein).

There is wide consensus among Presence and QoE researchers on the potential of multisensorial immersion to deliver an enhanced media experience. The Presence research community supports the hypothesis that the more extensive an immersive system is (i.e. in terms of the number of human senses engaged), the greater its capability to evoke Presence [49]. Similarly, QoE researchers encourage the development of sensorially-enriched media as a mean to enhance the user experience by stimulating senses other than sight and hearing [46]. A growing body of empirical evidence supports these theoretical premises. Sensory effects as odor, wind, vibration and light effects, as well as an enhanced audio quality, have been found to favour media enjoyment and to have a positive influence on the sense of Presence and on the perceived quality, relevance and reality of a multimedia experience [19, 25, 54, 74, 90, 94]. In particular, action movies, sports, news and documentaries are among the genres that could benefit the most from these solutions [95].

From a technical perspective, several works have shown that it is technically feasible to implement and deploy an end-to-end solution integrating sensory effects into a legacy system (see for instance the implementations in $[42,50,93,104])$. The development and official release of the MPEG-V standard (and in particular, of its Part 3 - Sensory Information [34]) represents an important step towards the leap of multi-sensorial media from experimentation to the digital services arena. The standard establishes the architecture and associated information 
representations for the interaction and interoperability between virtual worlds (i.e., multimedia content) and real worlds through various sensors and actuators. The Part 3 defines a set of sensory effects (e.g., light, temperature, wind, vibration, touch) and associated semantics to deliver multi-sensorial content in association with multimedia. Thus, multi-sensorial media emerges as a mean to deliver a new form of immersive experiences to the mass market in a non-disruptive manner. However, many questions remain concerning issues as the sensory effects that can better complement a given audiovisual content or the best way in which to integrate and combine them to enhance the user experience of a target audience segment.

In particular, scientific evidence on the impact of human factors on the user experience with multi-sensorial media is still insufficient and sometimes, contradictory. Furthermore, the associated implications, as regards to the potential adoption of these technologies, have been widely ignored. Previous works as those in $[2,44,53,97,101]$ point to a direct impact of factors such as extraversion, openness to experience, impulsivity, dissociation, locus of control and domain-specific interest and knowledge on the user experience with media. Most of them highlight also the mediating role of attentional processes in the elicitation of Presence. Contradictory results are reported, however, as regards to the influence of factors as focus (ability to concentrate on activities and block out distraction), psychological absorption, immersive tendency and neuroticism. Against this context, an empirically-supported framework enabling a systematic program of research on the subject would be highly useful to contextualize and consolidate previous results and to build further scientific knowledge.

The objective of the research presented in this paper is to gain insight into the impact of binaural audio and sensory (light and olfactory) effects on the sports media experience, both at the overall level (average effect) and as a function of users' characteristics (heterogeneous effects). To this aim, we conducted an experimental study exploring the influence of these immersive elements on the quality and Presence dimensions of the media experience. Along the quality dimension, we look for possible variations on the quality scores assigned to the overall media experience and to the media components content, image, audio and sensory effects. The potential impact on Presence is analyzed by looking at two of the four dimensions defined by Lessiter et al. [48]; Spatial Presence and Engagement. The users' characteristics considered encompass specific personal affective, cognitive and behavioral attributes, namely individuals' preferences and habits in relation to the content, knowledge of the involved technologies, tendency to get emotionally involved and tendency to get absorbed in an activity (blocking out external distractors), as well as the Big Five personality traits extraversion, agreeableness, conscientiousness, neuroticism and openness to experience.

In line with our goals and considering previous results in the state of the art, we hypothesize that:

H1 both binaural audio and sensory effects have a significant average effect on the Quality of Experience and on the dimensions of Presence;

H2 the impact of binaural audio and of sensory effects on:

a. the Quality of Experience is different for sports (football) fans and non-fans and across groups of participants with different levels of knowledge of involved technologies;

b. the level of Engagement is different for sports (football) fans and non-fans and across groups of participants with different levels of tendency to get emotionally involved, openness to experience, neuroticism and extraversion; and, 
c. the level of Spatial Presence is different for sports (football) fans and non-fans and across groups of participants with different levels of tendency to absorption and openness to experience.

Our findings are expected to contribute to a framework for systematic research on the user experience with multi-sensorial media. In particular, they could support the formulation of specific hypotheses addressing the potential of binaural audio and light and olfactory effects to enhance the sports media experience of different users segments as a function of their characteristics.

The remainder of this paper is organized as follows: Section 2 presents an overview of relevant work with regard to our approach and objectives; Section 3 details the experimental study conducted; Section 4 presents the outcomes of the three-step analysis developed; Section 5 discusses and contextualizes our results; and, Section 6 highlights open issues and research challenges and suggests specific hypothesis to be tackled in the future.

\section{Related work ${ }^{1}$}

\subsection{The media experience: presence, emotions and quality judgment}

Quality of Experience (QoE) research focuses on the factors and mechanisms that influence the subjective quality assessment of a multimedia asset (i.e. the content quality as perceived by an individual). The construct has been formalized as: "the degree of delight or annoyance of the user of an application or service (...) which results from the fulfillment of [his/her] expectations with respect to the utility and/or enjoyment of the application or service in the light of the his/her personality and current state" [46]. The factors influencing the QoE can be of contextual, technical and human nature. Contextual factors have been defined as those "that embrace any situational property to describe the user's environment" [41]. These not only concern the physical context, but also other dynamic or static features of economic, social or technical nature [46]. Technical factors (also known as system factors) refer to those conditioning the resulting technical quality of an application or service [41]. Different categories of system factors have been proposed in literature, both from a technical perspective, in which they are divided according to the related components of the service architecture/chain, and from a user perspective, considering their final influence/manifestation during the experience [11]. Last but not least, human factors comprise those features that characterize the user and have an influence on his/her perception of quality. The bounding effect of these factors in the perceived quality of a multimedia asset is discussed in Section 2.2.

The sense of Presence, defined as the subjective experience of being in one place even when the person is physically located in another [79], is at the core of research on user experience with entertainment technologies, with particular emphasis on interactive computergenerated applications. Presence has been found to be strongly related to the capability of a mediated environment - including 3DTV, videogames and artistic and cultural heritage virtual environments (VEs) - to elicit emotions [61, 90] and, in particular, enjoyment [73, 85]. In consequence, an enhanced sense of Presence is considered to have a direct impact on the adoption potential of these applications. 
The factors influencing Presence can be associated to the media form, the media content or the media users [49]. Media form is related to the extent and fidelity of sensory information and to the consistency between the sensory inputs/outputs presented through the different modalities [33, 49, 79]. In other words, it encompasses those features characterizing in an objective manner the capability of a specific software and hardware solution to deliver a rich and consistent multi-sensorial media content in a transparent manner (i.e. as an invisible medium).

Media content is a very broad category concerning issues such as the story, messages, objects, activities or characters presented. In particular, some content characteristics identified as determinants of Presence are: social realism, autonomous behavior and appearance of characters and objects, the ability to modify the physical environment and to anticipate the effect of an action and possible interactions between the type, nature and complexity of tasks or activities [33, 49, 69, 78].

As regards to the characteristics of the media user, Presence has been found to be significantly influenced by emotional, cognitive and motivational-behavioral factors, such as: immersive tendency (measured in terms of absorption and emotional involvement), attention, relevance, skill, perceived control, challenge, cognitive capabilities and personality traits $[1,17,47,57,86,97]$. Interestingly, these outcomes are in coherence with Nabi and Mrcmar's [55] theory of media enjoyment as an attitude discussed below. That is, although different in focus and approach, these works point to a strong interaction among the cognitiveaffective assessment of the media experience (i.e. expressed in the form of a holistic quality judgment of the media form and content components presented), the emotional response and the perceived level of physical Presence. We discuss further on the impact of human factors on the media experience in Section 2.2.

The most commonly used measures of Presence are based on subjective ratings through questionnaires [69]. Among the most prominent measuring tools are the Presence questionnaire developed by Slater and colleagues over a number of studies [89]; Witmer and Singer's Presence Questionnaire [102]; and the ITC Sense Of Presence Inventory (ITC-SOPI) developed by Lessiter et al. [48]. Whereas the former two questionnaires examine the sense of Presence in computer generated environments, the ITC-SOPI instrument was conceived to measure Presence-related facets of the user experience across a range of media, including television and cinema. A total of 604 individuals provided responses to the initial list of 63 Presence-related items. Using principal axis factoring analysis, Lessiter et al. extracted four factors: Sense of Physical Space (also known as Spatial Presence), Engagement, Ecological Validity (also referred as Naturalness), and Negative Effects. Taken together, the former two factors accounted for more than $25 \%$ of the variance. The Sense of Physical Space encompasses items referring to the sense of physical placement in the mediated environment and Engagement comprises items describing a tendency to feel psychologically involved and to enjoy the content.

\subsection{The bounding effect of human factors}

\subsubsection{Attitudes}

The psychological mechanisms underlying user experience with multimedia applications have been widely studied although not completely understood. In a holistic approach, Nabi and Mrcmar [55] conceptualize media enjoyment as an attitude, a broad psychological construct 
defined as "a relatively enduring organization of beliefs, feelings, and behavioral tendencies towards socially significant objects, groups, events or symbols" [32]. This approach is supported by a broad body of evidence on the influence of affective, cognitive and behavioral factors on individuals quality judgment of and emotional response to media $[55,60,75,87,96$, $105]$.

The tripartite structure of attitudes has been encompassed into the ABC model [21, 52]. The Affective dimension (A) refers to the individual's emotions in relation to the attitude object (in our analysis, the media content). This dimension has been studied mainly in terms of media enjoyment, which is at the core of the intrinsic motivations and effects of media use [71]. Media enjoyment has also been found to be linked to entertainment as a media effect, which at the same time correlates with some of the more frequently reported motivations for media use: arousal, to pass time, relaxation and to escape. In this sense, media provides a means to escape to a fantasy world where emotions can be experienced [71].

The Cognitive (C) components, which have been studied to a lesser extent, concern personal beliefs and knowledge in relation to the attitude object. Finally, the Behavior (B) dimension deals with the influence of attitude on behavior and encompasses forms as past or ongoing viewing experience and past behaviors or behavioral intentions in relation to the content [55]. The B dimension is frequently addressed under the assumption of consistency, which holds that an individual's behavior shall be consistent with his/her affective and cognitive attitudinal components. However, neither this principle nor a clear distinction between the $\mathrm{ABC}$ components have been supported by empirical research in a consistent manner [22, 45, 52].

According to Eagly and Chaiken [21] attitudes are critically expressed by "evaluating a particular entity with some degree of favor or disfavor" (i.e. by means of a quality judgment). In this sense, the attitudinal attribute structural consistency is analyzed in [91] to deal with a person's overall evaluation of an object, with the evaluative implications of his/her beliefs and emotional reactions to the object and with the multiple interactions among these. In particular, several authors emphasize the importance of attributes such as valence (positive or negative), the intensity (i.e. psychological significance) of attitudes and previous knowledge and experience in relation to the attitude object $[21,55,91]$. The relevance of measurement specificity (i.e. by clearly identifying the element to be assessed) is also highlighted in [55] as a means to properly contextualize the evaluation and therefore obtain more reliable assessments.

\subsubsection{Personal characteristics and personality traits}

Many different characteristics of the media user have been suggested to have an influence on the media experience. Along each of the three dimensions defined by the attitudes theory, these characteristics can be classified as encompassing from situation specific factors as mood before or during the media use [49] to more enduring features or states as personality traits [66]. However, empirical evidence about the role of personal characteristics on the user experience with media is still quite limited.

Situation specific factors may condition the physical, cognitive and affective state of the user immediately before or during the exposure to media and, in consequence, may have an important effect on the user experience. However, these factors are usually extremely dynamic and the variability of their impact across individuals can be very high. Furthermore, only a few of these variables, as may be visual fatigue derived from a deficient 3D production, can be controlled in a consistent manner by a technical system. Thus, predictions on the influence of 
state variables on the user experience are rarely included in a general model [101]. Conversely, enduring personal characteristics enable the characterization of the media user in a more consistent manner. In the following we present some of the most relevant factors found in the state of the art to have an influence on the user experience with media. The emphasis is on empirical studies.

In [49], Lombard and Ditton reviewed previous literature with the aim to identify factors that encourage or discourage a sense of Presence in media users. The factors analyzed encompass characteristics of media form, characteristics of media content, and characteristics of the media users. From the last group, the authors highlight knowledge and previous experience with media and personal relevance of the content as some of the user factors more likely to influence Presence.

According to the theoretical model proposed by Wirth et al. [101], the construction of Spatial Presence follows a two-stage process. The first level encompasses the construction of the spatial situation model; a mental model of the mediated situation that integrates spatialrelated information. According to the authors attention allocation plays a dominant role in this step, which is heavily affected by three main individual characteristics, namely psychological absorption, domain-specific interest and spatial visualization ability. Wirth et al. also identify intelligence, gender and age as other (secondary) user variables that could have an influence on the controlled (i.e. voluntary) allocation of attention. In the second level, Spatial Presence is generated by the confirmation of a specific perceptual hypothesis addressing the individual perception of self-location in (and frequently also of possible actions within) the depicted environment. Factors as individual cognitive involvement and willingness to suspend disbelief are considered to favour this process of perceptual hypothesis testing.

In [102] Witmer and Singer analyze, among other issues, how personal differences affect the perceived level of Presence. This was made in terms of immersion, under the assumption that the greater the sense of immersion the higher the level of Presence experienced by the user of a mediated environment. To measure the Immersive Tendency of an individual, Witmer and Singer propose the Immersive Tendency Questionnaire (ITQ). The structure and utility of the proposed scales were analyzed within and across four experiments involving 152 participants. The experiments combined different levels of task difficulty and environment complexity, as well as different types of visualization and interaction devices. A cluster analysis on the resulting data revealed three subscales, namely involvement (propensity to get involved passively in some activity), focus (ability to concentrate on enjoyable activities and block out distraction), and games (frequency of playing games and level of involvement in these games). Only two of the four experiments revealed a significant correlation between the reported levels of Immersive Tendency and Presence. However, a significant correlation between these measures was found by combining the data across experiments. Witmer and Singer's Immersive Tendency Questionnaire is one of the most widely used instruments to measure the personal tendency to get immersed in a mediated environment.

Similarly, the Big Five factors extraversion, agreeableness, conscientiousness, neuroticism and openness to experience are considered the most comprehensive dimensions of personality [40]. Extraversion implies an energetic approach toward the social and material world. That is, it measures to what extent an individual is oriented toward the external world (the opposite to introvert) and encompasses traits such as sociable, active, assertive, outgoing and emotionally positive. Agreeableness contrasts a prosocial and communal orientation towards others with antagonism. Agreeable persons can be generally described as trustful, helpful, altruist, tenderminded and modest. Conscientiousness describes socially prescribed impulse control that 
facilitates task- and goal-directed behavior. It is generally associated with individuals that that tend to think before acting, perform well following norms and rules, planning, organizing and prioritizing tasks and that are hard-working, reliable, organized and self-disciplined. The trait has been also related to an increased perceptual sensitivity. Conversely, neuroticism contrasts emotional stability and even-temperedness (low scores) with negative emotionality, such as feeling anxious, nervous, sad, and tense (high scores). People scoring high on neuroticism are usually nervous, insecure, anxious, vulnerable and excitable. Finally, openness to experience (vs. closed-mindedness) describes the breadth, depth, originality, and complexity of an individual's mental and experiential life. This factor is related to personality traits as adventurous, liberal, imaginative, receptive to new ideas and approaches and having a preference for variety $[5,38,39,63]$.

The work by Weibel et al. [97] analyzes the relation between immersion and the Big Five personality traits. The authors rely on Witmer and Singer's Immersive Tendency Questionnaire and on the NEO Five-Factor Inventory to measure the individuals' immersive tendency and personality traits, respectively. To examine the dimensionality of immersive tendency Weibel at al. conducted a factor analysis on the ITQ scale. In contrast to Witmer and Singer's classification, they obtained two factors that explained $17.32 \%$ and $8.11 \%$ of the variance. The first factor consists of five items that capture emotional reactions during media usage and during (day) dreaming and thus, it was classified as emotional involvement. The second factor was classified as absorption since it comprises four items that refer to focused attention, lost track of time perception and involvement in the sense of blocking out external distractors. Weibel et al. explored the connection between immersive tendency and the Big Five personality traits using structural equation modeling. The subdimension immersive tendency was found to be almost entirely determined by emotional involvement. The construct, as well as the subdimension emotional involvement, resulted to be positively correlated with openness to experience, neuroticism and extraversion. Neuroticism showed the highest influence. The three variables explained around one third of the variance of immersive tendency and of emotional involvement. Conscientiousness and agreeableness were not found to be related to immersive tendency. Interestingly, the subdimension absorption was found to be influenced only by openness to experience. In other words, individuals who score high on openness to experience are more prone to get emotionally involved in and to get absorbed by media than those who score low. Conversely, users with high scores on neuroticism and extraversion show an increased tendency to get emotionally involved only.

Sacau et al. [66] conducted an extensive literature review on the influence of human factors on Presence. The personal characteristics analyzed encompass categories as cognitive abilities, practice and demographic factors and personality traits. Within the first category the authors highlight memory and reasoning, spatial and psychomotor abilities and the capacity to identify and manipulate visual patterns. They hypothesize that these abilities may increase plot comprehension and enable a fluid navigation through and an enhanced perception of spatial sceneries, respectively. Concerning practice and demographic factors, Sacau et al. point to level of experience, domain specific knowledge, gender and age. As regards to the former factor, the authors hypothesize that experienced users are more able to focus attention on meaningful details of the mediated environment than naïve individuals. A similar effect is envisaged for general knowledge in relation to the content. Concerning this factor, the authors believe that it could have also a negative impact since experts are supposed to pay more attention to errors or wrong portrayals. The potential impact of gender and age on the user experience is suggested to be related to gender differences in spatial abilities and to the 
negative effect of age on individuals' capability to allocate attentional resources respectively (see [66] and citations thereof).

Sacau et al. examine several experimental works as those of Sas and O'Hare [67], Laarni et al. [44], Murray et al. [53] and Baños et al. [2]. Sas and O'Hare found a correlation between the personality factors psychological absorption, empathy and willing to suspend disbelief and the reported level of Presence. Laarni et al. [44] found a significant relation between Presence and factors as extraversion, impulsivity and focus (as defined by Witmer and Singer) and suggest that attentional processes may have a mediating role in the elicitation of Presence. Neuroticism, however, was not found to be correlated with Presence. The work by Murray et al. [53] revealed a significant correlation between Presence and two of the four factors analyzed: dissociation and locus of control. The other two factors, namely psychological absorption and immersive tendency were not found to be related with Presence. Conversely, Baños et al. [2] found that the higher the absorption susceptibility, the greater the level of Presence experienced by an individual. As pointed out by Sacau et al., although many of these works coincide on the instruments used to measure personality factors as absorption and immersion, there are significant differences among their approaches as regards to the Presence questionnaires used, the methodology followed, the media stimuli applied and the technical features of the visualization system employed to deliver it.

Jumisko Pyykkö [41] identifies three major user's characteristics that, according to previous works, have an impact on the Quality of Experience. These are user's relation with the content, quality expectations and knowledge about the characteristics of quality under study. Within the first category, personal interest in the content is highlighted as one of the factors with the highest influence. Concerning the last one, several works reveal that experienced evaluators are more critical and also more consistent in their evaluations than naïve assessors [28].

Scientific evidence on the influence of human factors on the user experience with media (and in particular, with multi-sensorial media) is still insufficient and sometimes, contradictory. An empirically-supported framework enabling a systematic program of research in this field is required to contextualize and consolidate previous results and to build further scientific knowledge.

\subsubsection{Multimodal perception}

From a broad psycho-physiological perspective quality judgment is framed by the human perception mechanism, which flows at two main levels: the early sensory processing level, aimed at extracting relevant features from the incoming multimodal sensory information, and the high-level cognitive processing level, focused on conscious interpretation and judgment $[26,41]$. Although this classification has been useful for analysis purposes, the boundaries between the two processing levels are not clearly established. In fact, the tight interactions between these two processes have shown to enable complex cognitive learning mechanisms such as the absorption of new knowledge [56] or the development of specialized (e.g. imagebased diagnosis) $[80,99]$ or general $[16,81]$ perceptual skills.

The mechanisms characterizing the processing of multiple simultaneous sensory inputs and their integration into a single, coherent and meaningful stimulus (i.e. multimodal perception), have not been entirely characterized yet. However, there is strong evidence of the integration and sharing of perceptual information since the very early sensory processing stages $[13,72]$ and of the modulating effect of factors such as knowledge, emotions, expectations, attitudes 
and goals on the relative importance of sensory modalities and their attributes, as well as on the orientation of attentional resources accordingly [6, 15, 37].

The presence of a given modality can distort or modulate (either intensifying or attenuating) the perception and relative importance of other modalities (see [72] and citations thereof). For instance, several works reveal complex bidirectional interactions between vision and sound, both in terms of the potential of vision to alter the perception of speech and the spatial location of audio sources and of the influence of audio on vision in terms of temporal resolution, intensity, quality, structure and interpretation of visual motion events [12, 51, 62, 68, 74]. Similarly, the sense of smell has been found to be influenced by other senses such as sight, hearing and touch [58]. Furthermore, it has the potential to evoke vivid memories and emotional reactions, it is mostly associated to personal relations and experiences and the related preferences are highly variable across individuals [31, 58, 100, 103]. Interestingly, smell technologies also raise health and privacy concerns as regards to the use of chemicals and to the possibility of misuse, respectively [58].

The majority of these empirical findings support the modality appropriateness hypothesis, which argues that the modality that is most appropriate or reliable with respect to a given task dominates the perception in the context of that task [98]. However, this and other approaches still require further elaboration to better explain complex effects such as the wide variety of responses to inter-sensory divergent events reported in literature.

\subsection{The impact of multi-sensorial immersion on the user experience}

The effectiveness of a mediated environment to evoke cognitive and emotional reactions in a similar way to non-mediated experiences is heavily conditioned by the consistency between the displayed environment and an equivalent real environment as regards to the user experience $[8,18]$. Two main components contributing to this realistic response are identified in [77]. These are: place illusion, defined as the subjective sense of being in a real place (i.e. Presence); and, plausibility illusion that refers to the illusion that the scenario being depicted is actually occurring, even when the person is cognitively aware of the fact that it is not. In this sense, the plausibility judgment is highly related to the capability of the system as a whole to produce events that are meaningful and credible as concerns to the individual's expectations [77].

The capability of a technical system "to deliver an inclusive, extensive, surrounding and vivid illusion of reality to the senses of a human participant" has been defined as immersion $[76,79]$. An immersive system can be characterized in terms of four major dimensions such as: inclusive, the extent to which it is able to isolate the physical reality; extensive, the range of sensory modalities addressed; surrounding, the extent to which the user is physically surrounded by the displayed environment; and, vivid, the resolution, fidelity and variety of the sensorial stimuli delivered through each sensory modality. Each of these dimensions can be present at different levels and scales [79, 83].

The independent and combined influence of system factors (including media form and content variables) on Presence and quality judgment has been analyzed extensively in scientific literature. For instance, the relative influence of narrative, interaction and immersion is qualitatively explored in [7] using omnidirectional video. Participants described transitions between the real and the displayed environment as disturbing and therefore, requiring a recalibration of the senses. Under this engaging experience, users found difficulties in following a story line (in particular at the beginning). The hand-based interaction put in place was qualified as highly intuitive and participants felt as if they were discovering and exploring 
the (mediated) environment. An interesting outcome of this study is the observed influence of immersion and interaction on the perception of narrative and vice versa. As highlighted by the authors, these components need to be carefully balanced to deliver a suitable framework for Presence.

As regards to the effect of specific system factors, an increased audio quality (e.g. through a realistic aural rendering of events or the use of auditory cues), is considered to have a significant impact on the sense of Presence and on the perceived QoE [30, 74, 90]. In [90], stereo and six-channel reproduction showed a strong positive impact on the emotional response and the reported levels of Presence and emotional realism. Similarly, the introduction of spatialized audio resulted in higher Presence scores in [30]. In [74], the relative influence of image quality (high definition vs. standard definition) and sound quality (Dolby 5.1 surround sound vs. Dolby stereo) on Presence and enjoyment is studied. No significant effects of image quality were found. In contrast, the impact of sound quality on Presence and enjoyment was shown to be significant.

Furthermore, a significant cross-modal influence of audio on visual quality and vice versa has been reported in [4, 27]. Beerends and Caluwe [4] found a bidirectional interaction between video and audio, being the influence of video quality on the perceived audio quality significantly (about six times) higher than the inverse effect. In coherence, the overall perceived audiovisual quality was found to be dominated by the video quality in nonconversational experiments. Hands [27] studied the relative influence of video and audio on the perceived quality of the overall audiovisual content. He conducted two experiments using musical audio-video and high-motion content. The analysis revealed that the overall quality of the audiovisual content results from the integration of audio and video qualities using a multiplicative rule. For the musical audio-video content the contribution of both modalities was significant, being the impact of audio quality slightly higher than the impact of video quality. For high motion content, however, video quality was weighted significantly higher than audio quality.

An opposite outcome is reported by Knoche et al. [43]. The authors conducted an experiment aimed at analyzing the image resolution and bitrate requirements for displaying multimedia content on mobile devices. The interaction between the perceived image and audio qualities was examined by considering four different image resolutions, seven video encoding bitrates, two audio bitrates and four content types. The authors found that the acceptability of the video was rated significantly higher at the lower audio bitrate. Surprisingly, this effect held constant across the full range of bitrates, image resolutions and content types.

Less traditional stimuli such as wind, vibration and light effects have also shown a significant impact on the user experience (both in terms of enjoyment and QoE), in particular with genres such as action movies, sports, news, documentary and to a lesser extent, commercials [19, 94, 95]. In [19], meaningful lighting effects complementing selected pieces of film and music were presented to a group of users. Participants believed that "lighting effects made watching movies or listening to music a very enjoyable and a more immersive experience". In [94], Waltl et al. explore the impact of wind, vibration and light effects on video at four different bitrates using a trailer of an action movie (high-motion content) and a nature documentary. On average, the 24 participants in the experiment valuated higher the video quality of the test sequences when sensory effects were present in comparison to the same sequence without sensory effects. Additionally, sensory effects were found to be more appreciated for documentaries than for action movies, being the difference between the Mean Opinion Score 
computed for the test sequences with and without sensory effects of 0.6 and 0.4 points respectively. In [59, 95], the same authors found a positive impact of these effects on the QoE and on the intensity of emotions like happiness, fun or fear.

Likewise, the sense of smell has the potential to evoke vivid memories and emotional reactions, it is mostly associated to personal relations and experiences, and the related preferences are highly variable across individuals [31, 58, 100, 103]. Interestingly, smell technologies also raise health and privacy concerns as regards to the use of chemicals and to the possibility of misuse, respectively [58]. Olfactory effects have been found to have a positive influence on the perceived quality, relevance and reality and on the reported enjoyment of a multimedia experience. Ghinea and Ademoye [25] propose the use of olfactory data as a mean to enhance the meaning and provide clarity of user presented information and increase the sense of reality and enjoyment in multimedia applications. To explore users' perception of olfaction-enhanced multimedia, the authors conducted an experiment using six video sequences; two cookery shows, three documentaries and one piece of news broadcast. Each test sequence was enhanced with a meaningful smell (different smells were used for each test sequence). Participants were asked to rate the impact of olfaction on the media experience in terms of issues as the perceived levels of relevance and reality, how distracting or annoying they find it and, the level of enjoyment experienced. Users reported that the scents emitted were relevant and heightened the sense of reality of the video. In general, they did not find the added olfactory media distracting or annoying. Conversely, although participants enjoyed slightly more the olfactoryenhanced media experience than the traditional one, the difference in the opinions of the two participant groups was not found to be significant.

\section{Experimental study}

As introduced before, the work presented in this paper has a twofold objective. We aim to: (i) explore the average impact of two immersive components, namely binaural audio (BA) and sensory effects (SE), on the user experience; and, (ii) reveal possible heterogeneities (if any) of these effects as a function of participants' characteristics and personality traits. Considering the similarity of our goals with those of industrial research, we inspired on previous works on experimentation in industry (see for instance [9, 10]) to design an experimental study addressing the abovementioned objectives.

In our experiment, we analyze the impact of binaural audio and sensory effects on the quality and Presence dimensions. Along the quality dimension, we look for possible variations on the quality scores assigned to the overall media experience (i.e. QoE) and to the media components content, image, audio and sensory effects (i.e., QoC, QoI, QoA and QoSE, respectively). The potential impact on Presence is analyzed by looking at two of the four dimensions defined by the ITC-SOPI questionnaire [48], namely Spatial Presence and Engagement. We also analyze the influence on these quality and Presence measures of a set of variables describing the following characteristics of individuals: preferences and habits in relation to the content, knowledge of the involved technologies, tendency to get emotionally involved and tendency to get absorbed in an activity and block out external distractors and the Big Five personality traits extraversion, agreeableness, conscientiousness, neuroticism and openness to experience. 
In line with our goals and considering previous results in the state of the art, we hypothesize that:

H3 both binaural audio and sensory effects have a significant average effect on the Quality of Experience and on the dimensions of Presence;

H4 the impact of binaural audio/sensory effects on:

a. the Quality of Experience is different for sports (football) fans and non-fans and across groups of participants with different levels of knowledge of involved technologies;

b. the level of Engagement is different for sports (football) fans and non-fans and across groups of participants with different levels of tendency to get emotionally involved, openness to experience, neuroticism and extraversion; and,

c. the level of Spatial Presence is different for sports (football) fans and non-fans and across groups of participants with different levels of tendency to absorption and openness to experience.

The following sub-sections describe in detail the materials and methods used in our experiment.

\subsection{Experimental set-up}

The end-to-end hybrid (internet-broadcast) 3DTV system described in [50] was deployed in a laboratory environment as illustrated in Fig. 1. The system was configured to transmit the additional content (i.e. BA and the control commands triggering the SE) encapsulated in the transport stream using the broadcast network. At the receiver side, this content is delivered using a local IP network that connects the receiver gateway with the visualization terminal and the sensory devices deployed. For a synchronous rendering of sensory effects we used presentation time stamps referred to the Program Clock Reference (PCR). In practice this configuration ensured a maximum delay of one second between a specified timestamp and the

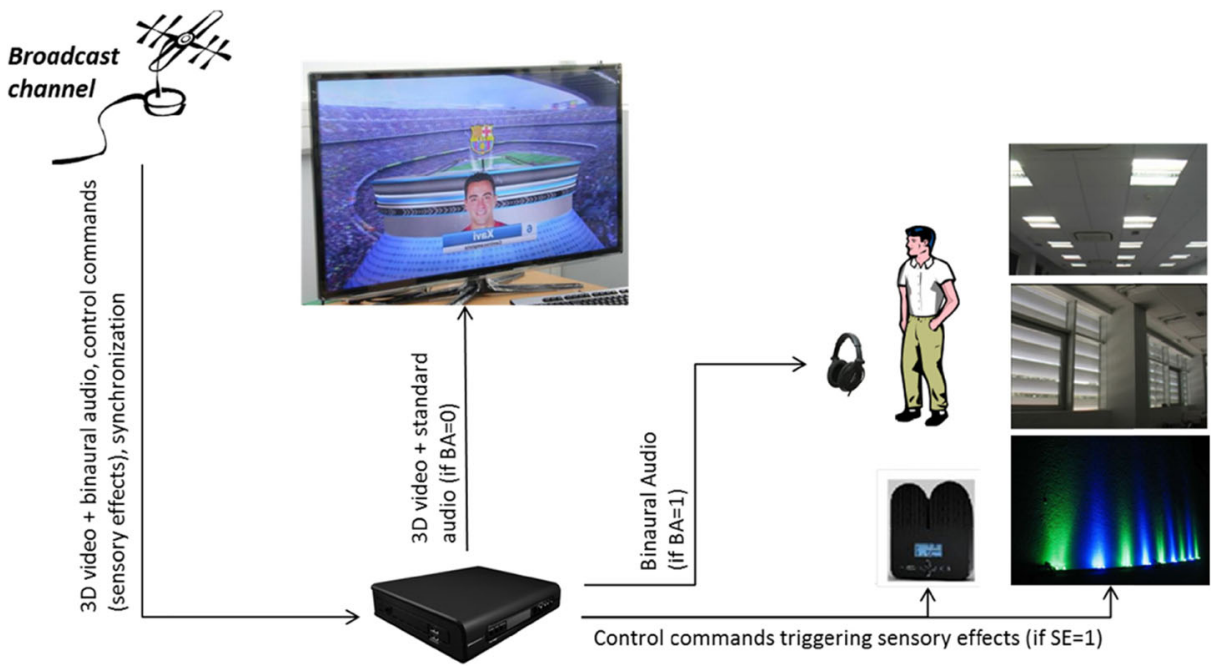

Fig. 1 Conceptual framework, high level architecture and main components of our test bed 
triggering of the corresponding sensory effect in the rendering device. For a detailed technical description of the implementation the reader is referred to [50].

The laboratory environment was set up to recreate a standard living room. The physical configuration of the room, including the relative position of the furniture and equipment, is depicted in Fig. 2. The viewing distance was equal to $3.5 \mathrm{~m}$ and the viewing angle was under $30^{\circ}$ as recommended in [44]. All the experiments are conducted under the same ambient conditions and avoiding any interruption. The LEDline unit was placed on the front of the sofa, attached all along the lower frame, just behind the observer's feet. The scent vaporizer was placed near the bottom-right corner of the TV screen at a distance of $3.2 \mathrm{~m}$ from the observer in the horizontal plane and at a height of $0.38 \mathrm{~m}$ from the floor.

The main features of the hardware and software components integrated in the set-up are summarized as follows (the number of units used is included in parenthesis):

- Control station: (1) Intel Xeon W3565 3.2 GHz, 6 GB RAM, Graphic card: NVIDIA GeForce GTX 5801536 MB GDDR5, Windows 7 (64 bits)

- Transmitter: (1) PROMAX MO-170 DVB-T; (1) DTU-225 FantASI USB-2 ASI/SDI Input Adapter (DekTec); (1) Intel Xeon 3.2 GHz, 2 GB RAM, NVIDIA Quadro FX 3000 $256 \mathrm{MB}$, Windows 7 (32 bits)

- Receiver: (1) Intel Core2 Duo CPU E7300 2.66 GHz 2 GB RAM, ASUS My Cinema DVB-T Card, Debian GNU/Linux 6.0. Kernel release: 2.6.32

- TV screen: (1) Samsung SmartTV 46" UE46F5700AW; (2) active stereoscopic glasses

- Sensory devices:

- (1) Headphones sennheiser HD 545 (used only when Binaural Audio is activated)

- (1) Olfactive Spirit Pro perfume diffuser with fragrance cartridge CUT GRASS

- (1) PHILIPS LEDline ${ }^{2}$ BCS722 48xLED-LP/WW 6, comprising 16 triads of nondimmable low power RGB LED units (color depth $=3$ )

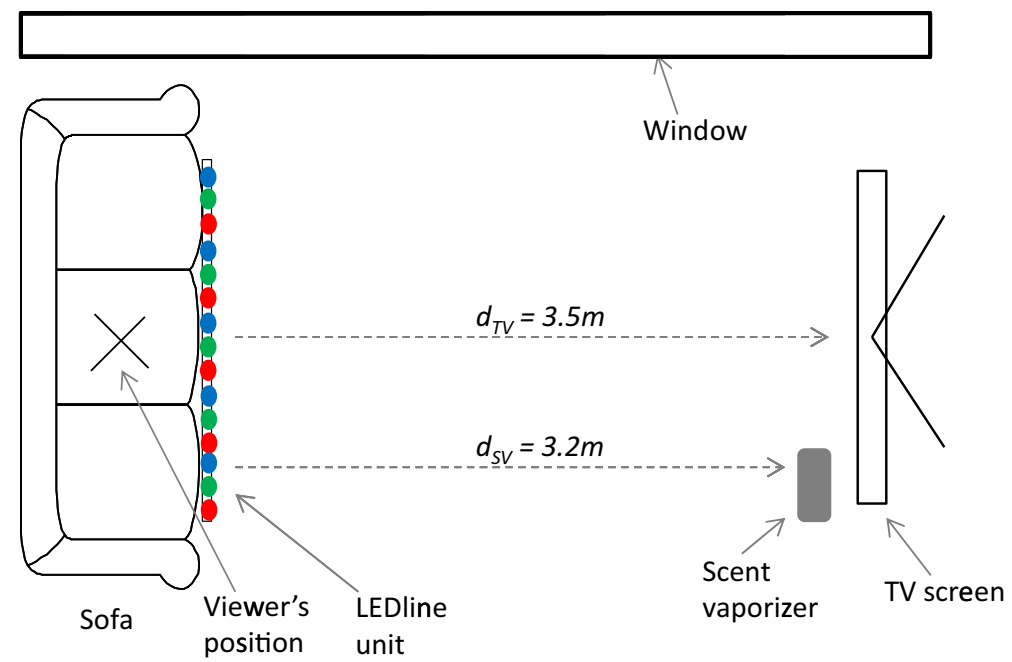

Fig. 2 Physical configuration of the test environment 
- KNX devices: (1) KNX/IP Router REG-K; (1) KNX/DALI Gateway REG-K/1/16(64)/ 64; (1) KNX Blind Actuator REG-K/4x/10

\subsection{Content}

The audiovisual content used presents a report of a premium football match between the Spanish teams F.C. Barcelona (FCB) and Real Madrid C.F. (RMCF). A setup of Panasonic LDK 800 cameras with Canon optics was deployed in the field to capture and producea stereoscopic video sequence of the game at $1920 \times 1080 \mathrm{i} 25 \mathrm{fps}$ side-by-side format. The video signal was pre-processed using a Stereoscopic Image Processor to minimize any undesirable 3D/image effect and was produced by a professional team at Eumovil S.L. following a professional sript. As a result, we obtained an extended report of the match similar to those used for a standard television transmission.

Concerning the game, it was a quite decisive match that had taken place more than six months before the beginning of the experiment (the championship had also ended by that time). Both teams generated and/or dominated rivalry moments and dramatic moves alternatively along the game. On the score, RMCF performed better than FCB during the first part (the intermediate score was RMCF $1-0$ FCB). During the second part each team scored one goal, being the final result RMCF $2-1$ FCB.

Numerous experimental studies have demonstrated that the time of exposure to stereoscopic images has a negative impact on several oculomotor functions (see for instance [23, 29, 84, 88]). In coherence, Rec. ITU-T BT.500-13 (p.8) recommends to keep the overall duration of a test session below $30 \mathrm{~min}$ (including explanations and preliminaries) to avoid the visual fatigue derived from the use of stereoscopic video. Considering the variety of quality and Presence related variables analyzed in our experiment (see Appendix 1) and our focus on the impact of the additional content introduced, minimizing visual fatigue seems critical to avoid a possible impact of this effect on user's valuations of the experience and of its elements. For this reason, the overall duration of the stereoscopic video content used in our experiments was shortened to be less than $30 \mathrm{~min}$.

To be able to present more than one configuration (i.e. experimental condition) to each participant without introducing an unnatural disruption in the game events, we decided to split the video into two independent but consecutive sequences showing relevant scenes from the first and second halves of the match. These sequences are referred from now on as test sequence 1 (TS1, duration: 11'30") and test sequence 2 (TS2, duration: 6'10"), respectively. To avoid possible variations produced by the influence of different genres in the indicators under study, we used these two test sequences as unique video content. As they were highly correlated in time and content, the only way to display a coherent evolution of events was by presenting them in the right order (see paragraph 1 in Section 5 of Rec. ITU-T P.911 [36]). Furthermore, as our focus was on the influence of the sensory effects integrated in our test-bed, the two sequences were presented with the same quality to all the assessors.

To complement the video content with an enhanced auditory stimulus we used a $3 \mathrm{D}$ binaural audio signal that simulates the acoustic environment of the football stadium using virtual audio sources. The audio signal was generated from the original audio recorded in the field using the algorithms described in [53]. The resulting audio is played using specialized headsets to evoke the feeling of being physically surrounded by the audio sources. The sensory effects (SE) presented comprise olfactory effects (i.e. vaporizing cut grass scent) and lighting 
Table 1 Sensory scenes and their associated sensory effects, rendering devices and triggering events

\begin{tabular}{|c|c|c|c|}
\hline $\begin{array}{l}\text { Sensory } \\
\text { scene }\end{array}$ & Sensory effect(s) & Rendering device(s) & Triggering game event \\
\hline Initial & $\begin{array}{l}\text { The room blinds are opened } \\
\text { The room lights are switched } \mathrm{ON}\end{array}$ & $\begin{array}{l}\text { Shutter control } \\
\text { Fluorescent lighting } \\
\text { control ballast }\end{array}$ & $\begin{array}{l}\text { Initial configuration of } \\
\text { the environment }\end{array}$ \\
\hline Game & $\begin{array}{l}\text { The room blinds are/remain closed } \\
\text { The room lights are/remain switched OFF } \\
\text { [If SE are activated] Ambient light color and } \\
\text { intensity } \\
\text { are fixed to create a relaxing atmosphere }\end{array}$ & $\begin{array}{l}\text { Shutter control } \\
\text { Fluorescent lighting } \\
\text { control ballast } \\
\text { LED-based ambient } \\
\text { lighting system }\end{array}$ & $\begin{array}{l}\text { Start of the game, end of } \\
\text { strategic moments }\end{array}$ \\
\hline $\begin{array}{l}\text { Game } \\
\text { event }\end{array}$ & $\begin{array}{l}\text { The room blinds remain closed } \\
\text { The room lights remain switched OFF } \\
\text { [If SE are activated] Ambient light color and } \\
\text { intensity } \\
\text { are controlled to create different illumination } \\
\text { atmospheres } \\
\text { [If SE are activated] Cut grass scent is vaporized }\end{array}$ & $\begin{array}{l}\text { Shutter control } \\
\text { Fluorescent lighting } \\
\text { control ballast } \\
\text { LED-based ambient } \\
\text { lighting system } \\
\text { Scent vaporizer }\end{array}$ & $\begin{array}{l}\text { Strategic moments of the } \\
\text { game: dramatic } \\
\text { moments of game } \\
\text { rivalry, shots, goals }\end{array}$ \\
\hline End & $\begin{array}{l}\text { The room blinds are opened } \\
\text { The room lights are switched OFF } \\
\text { [If SE are activated] Ambient light color and } \\
\text { intensity are switched OFF }\end{array}$ & $\begin{array}{l}\text { Shutter control } \\
\text { Fluorescent lighting } \\
\text { control ballast } \\
\text { Led-based ambient } \\
\text { lighting system }\end{array}$ & End of the game \\
\hline
\end{tabular}

effects, which comprise the automatic control of ambient lighting and of the room's lighting and blinds. In response to specific events registered during the football match, different actuator devices are triggered synchronously to deliver specific sensory scenes. For each sensory scene, Table 1 summarizes the associated triggering event, the sensory effects delivered and the actuator devices used to render each sensory effect. The sensory scenes were designed to deliver a meaningful combination of sensorial stimuli aimed at extending the perception of the game (in particular of relevant events) to senses other than sight and hearing. Thus, the frequency and duration of the sensory effects rendered in each case are in synchronization with those of the corresponding game events.

\subsection{Experimental design}

To explore the potential effect of BA and SE on the quality and Presence measures considered in our study, we defined the three experimental conditions shown in Table 2. These encompass one baseline condition (EC3) and two treatment conditions (EC1 and EC2). In the baseline condition participants were exposed to both sensory effects and binaural audio. In the treatment conditions EC1 and EC2, participants were exposed to BA only (i.e. SE were not administered) and to SE only (i.e. BA was not administered), respectively. In coherence, the impact of BA and SE is analyzed by comparing the scores assigned by the participants to the quality and Presence measures in EC1 and EC2 with respect to the baseline group EC3 (see Section 4). That is, we analyze the variation in the dependent variables across groups/ experimental conditions generated by the exclusion of each of the immersive components object of study (i.e. BA and SE).

In the first part of the experiment (corresponding to TS1), each participant is assigned randomly (simple random assignment) to one experimental condition from the three options 
available. Similarly, he/she is assigned randomly to one of the two remaining conditions for the second part of the experiment (TS2). Participants did not know in which conditions they were at the moment they participate in the experiment (see the recruiting e-mail and the explanation provided before the experiment in Appendixes 2 and 3 respectively). The combination of the random assignment procedure and the $3 \times 2$ configuration adopted ensures that being exposed to a given experimental condition is statistically independent from the characteristics of the individuals or the context (see Section 3.5). Furthermore, the kind, number and order of the impairments (in our study, sensory effects) presented to each participant is given by the components enabled under the assigned experimental condition and by the triggering events in the corresponding test sequence. This design is expected to minimize the contextual effects described in Appendix 3 to Annex 1 of Rec. ITU-T BT.500-13.

\subsection{Procedure}

We used a self-developed procedure inspired by ITU-T Recommendation P.911 [ITU-T 1998], by ITU-R Recommendations BT.1438 [ITU-R 2000] and BT.500 [ITU-R 2002] and by previous research on QoE (for a state-of-the-art review see [41]).

For recruiting participants, we e-mailed our colleagues at several research centers and departments at the Technical University of Madrid asking for volunteers to participate in the experiment. The e-mail, which is included in Appendix 2, provided a general description of the goals of the experiment but did not reveal any detail on the content or the specific components to be valuated. A Tablet PC was raffled off among the participants.

Prior to the session, volunteers provided informed consent to participate in the study and were screened for determining exclusion criteria. They were checked for having (corrected-to) normal visual acuity and stereopsis. They were also required to score lower than 18 on the Beck Depression Inventory [3], to have a history free of neurological disease, head injury, learning disability and mental or psychological disorder, not to be using any medication for psychological or emotional problems, and not to be using any drug that could affect cognitive capabilities. None of them was involved in the work under evaluation.

Eligible participants were provided with the Personal characteristics questionnaire (see Appendix 1) in advance and were asked to bring it filled when they came to the lab for the experiment. All participants were tested individually. All the experiments were conducted under the same ambient conditions and avoiding any interruption.

Once in the laboratory, the participant was invited to sit down comfortably on a sofa and the following steps were followed:

1. We initiated the experiment with an explanation of the goals of our study and of the procedure to be followed. To avoid response bias, we did not reveal any detail on the content or the specific sensory effects to be presented. Furthermore, we highlighted the exploratory character of our study (in the sense that it was aimed to explore the effect of

Table 2 Map of experimental conditions

\begin{tabular}{ll}
\hline Experimental condition & Immersive component(s) presented \\
\hline EC1 & BA administered; SE not administered \\
EC2 & BA not administered; SE administered \\
EC3 & Both BA and SE administered \\
\hline
\end{tabular}


the components to be presented, not to validate the implemented setup) and emphasized the importance of providing faithful valuations. The specific explanation given to the participants is included in Appendix 2. The participant was invited to formulate any question he/she may have and the issues raised were clarified at the same "general" level than the previous explanation. The user was finally invited to enjoy the experience freely.

2. The first test sequence was launched under the first experimental configuration assigned to the participant. Immediately, the room is automatically configured to enhance the viewing conditions: the fluorescent lights are turned off and the shutter blinds are closed. If binaural audio is activated, it is delivered through the specialized headsets indicated above. If sensory effects are activated, the ambient lighting is turned on and its color is regulated to create a calm and relaxing atmosphere. Cut grass scent is vaporized and lighting effects are triggered at strategic moments of the game as shown in Table 1. Once the scent is emitted, it naturally fades until the end of the session when the blinds are automatically opened and the room is ventilated for $15 \mathrm{~min}$ (one session corresponds to one EC).

3. Immediately after the end of the test sequence, the participant was asked to fill in the ITCSOPI and quality assessment questionnaires (aclaratory notes on the specific issues encompassed by each component to be valuated were included in the quality assessment questionnaire, see Appendix 1)

4. TS2 was launched under the second experimental configuration assigned to the user, with similar effects on the room as those described in step 2

5. Finally, step 3 was repeated.

Before the session, the former procedure was tested with five individuals and operational details were further refined to ensure a smooth course of the experiment. The data corresponding to these individuals were not included in our analysis.

\subsection{Sample and data}

Forty-seven eligible individuals were recruited for the study: 34 males and 13 females. The participants were aged between 18 and 54 years $(X=29.6, S D=8.68)$, being around $70 \%$ of them between the ages of 20 and 35 . The sample comprised undergraduate students $(37 \%)$, postgraduate researchers $(50 \%)$ and post-doc researchers and university professors $(13 \%)$. Considering that the majority of volunteers came from the (engineering) research university environment, it is not a surprise that the sample resembles the demographic composition of this environment in terms of sex, age, occupation and probably also, knowledge of the involved technologies.

From the combination of the random assignment procedure and the $3 \times 2$ configuration described above (see Section 3.3) we obtained a roughly homogeneous distribution of the sample with approximately $2 / 3$ of exposures and $1 / 3$ of non-exposures to each immersive component. The distribution of participants across experimental conditions in each test sequence and the number of individuals following each possible order of exposure are shown in Tables 3 and 4 respectively.

As discussed before, the combination of the random assignment procedure and the $3 \times 2$ configuration adopted (see Section 3.3) was expected to ensure that being exposed to a given experimental condition is statistically independent from the characteristics of the individuals. We confirmed this premise through mixed-design ANOVAs and chi-squared tests comparing 
the individuals assigned to the different experimental conditions in terms of the user characteristics collected. There were no significant differences (at the $p<0.05$ level) between the individuals assigned to the three experimental conditions with respect to their characteristics.

The statistics of the personal characteristics and personality factors obtained from participants' answers to the Personal characteristics questionnaire are presented in Tables 5, 6, 7, and 8.

As expected, the majority of participants ( $83 \%$ of individuals) reported to have some knowledge of the technologies integrated in the experimental set-up. Fans and non-fans were almost equally represented, considering the good balance of the sample in terms of football preferences and of frequency of viewing. In contrast, the distribution of participants in terms of team preference is quite biased. As shown, most individuals did not favour any team or favoured other teams not involved in the game displayed (59.6\%). The rest of the sample favoured RMCF in a first place (34\%) and FCB to a lesser extent $(6.4 \%)$. A quick inspection to the dataset reveals that most football fans identified RMCF as their favourite team (a quite predictable outcome considering that the volunteers live and work/study in Madrid), whereas the majority of non-fans reported not to favour any team. Thus, although it can not be claimed that the collected sample is statistically representative of the general population, it does encompass a quite similar number of individuals that like and do not like the content. Considering the influence of this factor on the media experience (see Section 2 for a discussion on the impact of plot and narrative on the user experience), the authors consider that the sample is valid enough to support the exploratory analysis proposed in this paper.

The factors quantifying the tendency to get emotionally involved and the tendency to get absorbed in the sense of blocking out external distractors (see Table 8) were computed as described in [97] from the answers of each participant to the ITQ questionnaire [102]. These two variables, as well as the Big Five factors extraversion, agreeableness, neuroticism and openness to experience resulted to be normally distributed whereas the distribution of conscientiousness was approximately normal.

In a preliminary exploration we conducted a multivariate analysis on the quantitative independent variables listed above. We aimed to reveal possible interactions between the affective, cognitive, and behavioural factors used to characterize the individuals in our study and, to identify highly correlated variables that could potentially hinder the soundness of the statistical analysis to be conducted. The results are reported in Section 4 of the Appendix. Individual preferences and habits in relation to the content were found to be positively correlated $(\mathrm{r}=0.75 ; \mathrm{p}=0.00)$ at the $\mathrm{p}<0.05$ level. This outcome points to a consistent behavior of participants in relation to their reported preferences, which supports the consistency theories found in literature (see Section 2.1). That is, those users with a higher level of preference towards the content have a tendency to watch football matches more frequently than those who do not like the content or who like it to a lesser extent. As previously reported in [97], the

Table 3 Number of participants assigned to each experimental condition and test sequence

\begin{tabular}{lllr}
\hline & TS1 & TS2 & Total \\
\hline $\mathrm{EC} 1(\mathrm{BA}=1 ; \mathrm{SE}=0)$ & 16 & 14 & 30 \\
$\mathrm{EC} 2(\mathrm{BA}=0 ; \mathrm{SE}=1)$ & 16 & 17 & 33 \\
$\mathrm{EC} 3(\mathrm{BA}=1 ; \mathrm{SE}=1)$ & 15 & 16 & 31 \\
Total & 47 & 47 & \\
\hline
\end{tabular}


Table 4 Number of participants following each possible order of assignment

\begin{tabular}{ll}
\hline Order of assignment & $\mathrm{N}^{\circ}$ of participants \\
\hline EC1-EC2 & 9 \\
EC1-EC3 & 7 \\
EC2-EC1 & 7 \\
EC2-EC3 & 9 \\
EC3-EC1 & 7 \\
EC3-EC2 & 8 \\
Total & 47 \\
\hline
\end{tabular}

tendency to get emotionally involved resulted to be negatively correlated with the Big Five personality factor extraversion.

From the two experimental conditions presented to each of the 47 participants we obtained the dependent quality and Presence measures shown in Table 9. The two valuations provided by each individual resulted in a total of 94 samples per variable, which were not correlated in time and therefore can be treated as independent measures. The dependent variables were tested for normality using the Shapiro-Wilk test [64, 70], histograms and normal Q-Q plots. The distribution of SP, Eng and QoSE was found to be normal and the distribution of QoE, QoI, QoC and QoA resulted to be approximately normal.

\section{Results}

As introduced before, the objective of our experiment is twofold. Our first goal is to explore the average effect of the immersive elements BA and SE on the dependent measures analyzed. That is, on Spatial Presence and Engagement and on the Quality of the media Experience and of its components, as perceived by the user. In a second step, we aim to reveal possible heterogeneities (if any) of these effects as a function of the individual characteristics and personality traits considered. In this section we specify the models that we used to analyse the data described above, and report results towards these two objectives. We start by discussing a base model focused on our first goal. Then, we incorporate individuals' characteristics to identify those with a direct impact on the dependent measures. Finally, we interact the immersive elements BA and SE with the individuals' factors to reveal whether the latter may have or not a modulating effect on the perceived impact of BA or SE. All models were coded and estimated in STATA [82] using Ordinary Least Squares (OLS).

Table 5 Question and responses on knowledge of involved technologies

\begin{tabular}{lccccc}
\hline Question & 1: None & 2: Basic & 3: Intermediate & 4: Expert & Total \\
\hline $\begin{array}{l}\text { How would you rate your current } \\
\text { level of knowledge on video, audio } \\
\text { or home automation technologies? }\end{array}$ & $17.0 \%$ & $40.4 \%$ & $36.2 \%$ & $6.4 \%$ & $100 \%$ \\
\hline
\end{tabular}


Table 6 Questions and responses on preferences and habits in relation to the content

\begin{tabular}{lllllll}
\hline Question & 1: Not at all & 2: Not much & 3: Neutral & 4: Somewhat & 5: Very much & Total \\
\hline $\begin{array}{l}\text { How much do you } \\
\text { like football? }\end{array}$ & $34.0 \%$ & $14.9 \%$ & $4.3 \%$ & $12.8 \%$ & $34.0 \%$ & $100 \%$ \\
$\begin{array}{c}\text { How frequently do } \\
\text { you watch football } \\
\text { matches? }\end{array}$ & $25.5 \%$ & $21.3 \%$ & $4.3 \%$ & $21.3 \%$ & $27.6 \%$ & $100 \%$ \\
\hline
\end{tabular}

\subsection{Base model}

In this section we measure the impact of SE and BA on participants by analyzing the average variation in the self-stated quality and Presence scores reported by individuals in EC1 and EC2 with respect to the baseline group EC3. That is, we analyze the variation in the perceived quality and Presence across groups/experimental conditions generated by the absence of each of the immersive components object of study (i.e. BA and SE).

The absence of BA and SE were coded as dummy variables taking value of one if BA/SE was absent in the experiment. Table 10 shows the estimated impact of the absence of BA and of SE on the perceived quality measures (i.e. overall Quality of Experience, Quality of Content, Image, Audio and Sensory Effects). Similarly, Table 11 shows the estimated impact of the absence of BA and of SE on the two dimensions of Presence considered (i.e. Spatial Presence and Engagement).

On average, the exclusion of SE or BA from the experimental condition did not cause significant variations neither on the perceived QoE, QoC, QoI or QoSE, nor on the dimensions of Presence. That is, those individuals who were randomly allocated to the groups where BA or SE were not administered did not report, on average, systematically different valuations for these measures in the corresponding Likert scale relative to those in the baseline group (where both BA and SE were present). Conversely, as shown in Table 10, the absence of binaural audio had a negative impact on the perceived Quality of Audio. Those individuals who were exposed to binaural audio assigned higher valuations to the QoA in comparison to those who were not exposed to this immersive component (standard stereo audio was used instead).

\subsection{Introducing characteristics of respondents}

After analysing the average variation in the quality and Presence measures associated with the absence of each of the immersive components (i.e. BA and SE), we explore the impact of the observed characteristics of individuals on these dependent variables (see Appendix 1 for a complete list of variables collected from individuals in the experiment). We look for systematic differences in the dependent measures (i.e. the perceived Quality of the Experience and of its components and the two dimensions of Presence analyzed) associated to each participant's characteristic. Individuals' preferences in relation to the content were coded as a new dummy variable named 'Football fan', which takes value of one for those participants who liked football

Table 7 Question and responses on team preference

\begin{tabular}{lccccc}
\hline Question & 1: RMCF & 2: FCB & 3: Other & 4: None & Total \\
\hline $\begin{array}{l}\text { Select the option that best } \\
\text { describes your football team preference }\end{array}$ & $34 \%$ & $6.4 \%$ & $19.2 \%$ & $40.4 \%$ & $100 \%$ \\
\hline
\end{tabular}


Table 8 Statistics of the personal characteristics and personality factors obtained from participants' answers to the Personal characteristics questionnaire

\begin{tabular}{llllll}
\hline & $N$ & Mean & SD & Min. value & Max. value \\
\hline Tendency to emotional involvement & 47 & 4.21 & 1.16 & 1.8 & 6.8 \\
Tendency to absorption & 47 & 5.02 & 0.98 & 2.75 & 6.75 \\
Extraversion & 47 & 2.46 & 0.92 & 1.0 & 4.67 \\
Agreeableness & 47 & 3.76 & 0.66 & 2.25 & 5.0 \\
Conscientiousness & 47 & 2.95 & 0.90 & 1.5 & 4.75 \\
Neuroticism & 47 & 2.37 & 0.81 & 1.0 & 4.0 \\
Openness to experience & 47 & 3.94 & 0.75 & 2.0 & 5.0 \\
\hline
\end{tabular}

very much or somewhat (group of football fans) and zero otherwise (group of non-fans). A dummy variable was also defined from the reported team preferences to consider the potential impact of favouring the winner team. It takes value of one if the individual favour RMCF and zero otherwise. Conversely, the possible effect of favouring the defeated team could not be considered due to the small number of FCB's fans that participated in the experiment (see Section 3.5 for a detailed description of the sample). Finally, we introduce the dummy variable 'Female' to account for possible gender-related effects. Tables 12 and 13 present the estimates corresponding to the quality and Presence measures considered, respectively.

There are not significant changes, with regard to the base model, on the estimates describing the impact on the quality scales of excluding BA or SE from the experimental condition. The inclusion of participants' characteristics, however, produces a significant improvement in the explanatory power of the models describing the different quality measures, as revealed by the R-squared and F-statistic.

We found a systematic impact of the dummy variable 'Football fan' on the perceived Quality of Experience, Content, Image and Sensory Effects. That is, on average, football fans assigned higher quality scores to the Content, Image and Sensory Effects than non-fans. This group also showed a tendency to assign higher valuations to the Quality of the overall Experience than the group of non-fans. Taken together, these outcomes suggest that, in the context of a multi-sensorial media experience, quality judgment is modulated by the level of personal preferences in relation to the content.

Previous knowledge of the involved technologies was found to have a positive impact on the perceived Quality of Content and a negative effect on the perceived Quality of Audio. On average, those participants with high levels of technological knowledge assigned higher scores

Table 9 Statistics of the presence and quality measures gathered during the experiment

\begin{tabular}{lllllr}
\hline & $N$ & Mean & SD & Min value & Max. value \\
\hline SP & 94 & 3.09 & 0.58 & 1.69 & 4.46 \\
Eng & 94 & 3.45 & 0.56 & 2.0 & 4.62 \\
QoE & 94 & 7.79 & 1.28 & 3.0 & 10.0 \\
QoC & 90 & 6.37 & 1.89 & 2.0 & 9.0 \\
QoI & 91 & 8.03 & 1.48 & 3.0 & 10.0 \\
QoA & 94 & 8.21 & 1.46 & 3.0 & 10.0 \\
QoSE & 58 & 7.09 & 1.65 & 3.0 & 10.0 \\
\hline
\end{tabular}


Table 10 Base quality models

\begin{tabular}{llllll}
\hline Variables & $\begin{array}{l}\text { Quality of } \\
\text { experience }\end{array}$ & $\begin{array}{l}\text { Quality of } \\
\text { content }\end{array}$ & $\begin{array}{l}\text { Quality of } \\
\text { image }\end{array}$ & $\begin{array}{l}\text { Quality of } \\
\text { audio }\end{array}$ & $\begin{array}{l}\text { Quality of } \\
\text { sensory effects }\end{array}$ \\
\hline $\begin{array}{rlll}\text { BA was } \\
\text { not present }\end{array}$ & -0.248 & 0.042 & -0.022 & $\mathbf{- 0 . 8 2 0 * *}$ & 0.029 \\
SE was & $(0.328)$ & $(0.503)$ & $(0.392)$ & $\mathbf{( 0 . 3 6 4 )}$ & $(0.437)$ \\
$\quad$ not present & 0.013 & 0.067 & -0.029 & -0.033 & $(0.369)$ \\
Constant & $(0.333)$ & $(0.511)$ & $(0.398)$ & $8.517 * * *$ & $7.071^{* * *}$ \\
& $7.793 * * *$ & $6.333^{* * *}$ & $7.929 * * *$ & $(0.265)$ & $(0.314)$ \\
Observations & $(0.240)$ & $(0.370)$ & $(0.286)$ & 93 & 58 \\
R-squared & 93 & 89 & 90 & 0.070 & 0.000 \\
$F$ test $(p$-value $)$ & 0.009 & 0.000 & 0.000 & 0.039 & 0.948 \\
\hline
\end{tabular}

Standard errors in parentheses. Bold print indicates relevant effects discussed below

$* * * p<0.01, * * p<0.05, * p<0.1$

to the Quality of Content than those with low levels. In contrast, the former were more critical about the Quality of Audio than those with less technological knowledge.

The tendency to get emotionally involved was found to have a significant influence on the perceived Quality of Sensory Effects. Those individuals with higher tendency to get emotionally involved were more prone to valuate high the QoSE than those with lower tendency. The QoSE was also influenced significantly by two personality traits, namely conscientiousness and openness to experience. On average, those individuals who scored high on these traits assigned higher valuations to the QoSE than those who scored low.

As for the quality measures, we looked for systematic differences in the perceived levels of Spatial Presence and Engagement associated to each participant's characteristic (see Table 13).

As in the previous cases, the inclusion of participants' characteristics produces a significant improvement in the explanatory power of the models describing the different dimensions of Presence, as revealed by the R-squared and the F-statistic. A significant change with regard to the base model emerges, however, on the estimates describing the impact on Spatial Presence of excluding sensory effects from the experimental condition. As shown, the absence of SE

Table 11 Base presence models

\begin{tabular}{lll}
\hline Variables & Spatial presence & Engagement \\
\hline BA was not present & -0.0194 & -0.116 \\
& $(0.142)$ & $(0.139)$ \\
SE was not present & -0.220 & -0.0241 \\
& $(0.144)$ & $(0.141)$ \\
Constant & $3.168^{* * *}$ & $3.502^{* * *}$ \\
& $(0.105)$ & $(0.103)$ \\
Observations & 94 & 94 \\
R-squared & 0.030 & 0.008 \\
$F$ test $(p$-value) & 0.247 & 0.682 \\
\hline
\end{tabular}

Standard errors in parentheses. Bold print indicates relevant effects discussed below

$* * * p<0.01, * * p<0.05, * p<0.1$ 
Table 12 Quality models including characteristics of individuals

\begin{tabular}{|c|c|c|c|c|c|}
\hline Variables & $\begin{array}{l}\text { Quality of } \\
\text { experience }\end{array}$ & $\begin{array}{l}\text { Quality of } \\
\text { content }\end{array}$ & $\begin{array}{l}\text { Quality of } \\
\text { image }\end{array}$ & $\begin{array}{l}\text { Quality of } \\
\text { audio }\end{array}$ & $\begin{array}{l}\text { Quality of } \\
\text { sensory effects }\end{array}$ \\
\hline BA was not present & $\begin{array}{l}-0.381 \\
(0.311)\end{array}$ & $\begin{array}{l}-0.192 \\
(0.432)\end{array}$ & $\begin{array}{l}-0.115 \\
(0.369)\end{array}$ & $\begin{array}{l}-0.788 * * \\
(0.354)\end{array}$ & $\begin{array}{l}0.0515 \\
(0.375)\end{array}$ \\
\hline SE was not present & $\begin{array}{l}-0.148 \\
(0.316)\end{array}$ & $\begin{array}{l}-0.117 \\
(0.438)\end{array}$ & $\begin{array}{l}-0.200 \\
(0.376)\end{array}$ & $\begin{array}{l}-0.0700 \\
(0.358)\end{array}$ & \\
\hline Football fan & $\begin{array}{l}0.809 * * * \\
(0.254)\end{array}$ & $\begin{array}{l}2.162 * * * \\
(0.369)\end{array}$ & $\begin{array}{l}0.977 * * * \\
(0.302)\end{array}$ & $\begin{array}{l}0.507 * \\
(0.290)\end{array}$ & $\begin{array}{l}1.077 * * * \\
(0.377)\end{array}$ \\
\hline Knowledge on technology & & $\begin{array}{l}0.486 * * \\
(0.220)\end{array}$ & & $\begin{array}{l}-0.393 * * \\
(0.174)\end{array}$ & \\
\hline $\begin{array}{l}\text { Tendency to Emot. } \\
\text { involvement }\end{array}$ & & & & & $\begin{array}{l}0.722 * * * \\
(0.176)\end{array}$ \\
\hline $\begin{array}{l}\text { Personality factor: } \\
\text { agreeableness }\end{array}$ & & & $\begin{array}{l}0.409 * \\
(0.227)\end{array}$ & & $\begin{array}{l}0.567 * \\
(0.329)\end{array}$ \\
\hline $\begin{array}{l}\text { Personality factor: } \\
\text { conscientiousness }\end{array}$ & $\begin{array}{l}0.268 * \\
(0.142)\end{array}$ & & & & $\begin{array}{l}0.499 * * \\
(0.212)\end{array}$ \\
\hline $\begin{array}{l}\text { Personality factor: } \\
\text { neuroticism }\end{array}$ & & & & & $\begin{array}{l}-0.477 * \\
(0.251)\end{array}$ \\
\hline $\begin{array}{l}\text { Personality factor: } \\
\text { openness }\end{array}$ & & & & & $\begin{array}{l}0.620 * * \\
(0.259)\end{array}$ \\
\hline Female & & $\begin{array}{l}0.733^{*} \\
(0.425)\end{array}$ & & & \\
\hline Constant & $\begin{array}{l}6.725^{* * *} \\
(0.470)\end{array}$ & $\begin{array}{l}4.641 * * * \\
(0.507)\end{array}$ & $\begin{array}{l}6.010^{* * *} \\
(0.901)\end{array}$ & $\begin{array}{l}8.799 * * * \\
(0.357)\end{array}$ & $\begin{array}{l}-1.193 \\
(2.152)\end{array}$ \\
\hline Observations & 93 & 89 & 90 & 93 & 58 \\
\hline R-squared & 0.145 & 0.300 & 0.141 & 0.158 & 0.369 \\
\hline$F$ test ( $p$-value) & 0.008 & 0.000 & 0.011 & 0.004 & 0.001 \\
\hline
\end{tabular}

Standard errors in parentheses. Bold print indicates relevant effects discussed below $* * * p<0.01, * * p<0.05, * p<0.1$

produces a negative impact on the level of Spatial Presence reported by participants. In other words, those participants who were randomly allocated to the groups where SE was not administered experienced, on average, systematically lower levels of Spatial Presence than those in the groups where SE was present. The fact that this effect emerges now and not in the baseline model highlights the magnitude and complexity of the role of personal characteristics on the user experience. By introducing the characteristics of respondents we control for the effect of individual differences (in terms of the observed features), thereby this previously masked impact is disclosed.

As regards to the influence of individual preferences, our models reveal that football fans felt systematically more emotionally engaged during the media experience than non-fans. Team preference was found to have also a significant impact on Presence. Those participants who favoured the winner team (i.e. RMCF) reported systematically higher levels of Spatial Presence and Engagement than those who favoured other teams.

The knowledge of involved technologies was found to have a positive impact on the level of Engagement. In this sense we argue that the interest of technology knowledgeable individuals in the technological innovations integrated in our testbed contributed to enhance their level of 
Table 13 Presence models including characteristics of individuals

\begin{tabular}{|c|c|c|}
\hline Variables & Spatial presence & Engagement \\
\hline BA was not present & $\begin{array}{l}-0.106 \\
(0.125)\end{array}$ & $\begin{array}{l}-0.199 * \\
(0.114)\end{array}$ \\
\hline SE was not present & $\begin{array}{l}-0.299 * \% \\
(0.128)\end{array}$ & $\begin{array}{l}-0.167 \\
(0.115)\end{array}$ \\
\hline Football fan & & $\begin{array}{l}0.259 * * \\
(0.116)\end{array}$ \\
\hline Favourite team $=\mathrm{RMCF}$ & $\begin{array}{l}0.459 * * * \\
(0.111)\end{array}$ & $\begin{array}{l}0.317 * * \\
(0.122)\end{array}$ \\
\hline Knowledge on Technology & & $\begin{array}{l}0.154 * * * \\
(0.058)\end{array}$ \\
\hline Emotional involvement & & $\begin{array}{l}0.156 * * * \\
(0.046)\end{array}$ \\
\hline Tendency to absorption & $\begin{array}{l}0.109 * * \\
(0.054)\end{array}$ & \\
\hline Personality factor: Extraversion & $\begin{array}{l}0.0687 \\
(0.059)\end{array}$ & $\begin{array}{l}0.164 * * * \\
(0.055)\end{array}$ \\
\hline Personality factor: Neuroticism & $\begin{array}{l}0.192 * * * \\
(0.068)\end{array}$ & \\
\hline Personality factor: Openness & $\begin{array}{l}0.124 * \\
(0.070)\end{array}$ & \\
\hline Constant & $\begin{array}{l}1.406^{* * * *} \\
(0.409)\end{array}$ & $\begin{array}{l}2.087 * * * \\
(0.288)\end{array}$ \\
\hline Observations & 94 & 94 \\
\hline$R$-squared & 0.310 & 0.393 \\
\hline$F$ test ( $p$-value $)$ & 0.000 & 0.000 \\
\hline
\end{tabular}

Standard errors in parentheses. Bold print indicates relevant effects discussed below

$* * * p<0.01, * * p<0.05, * p<0.1$

Engagement. Two straightforward results, which are in coherence with previous outcomes, are the positive effects of the tendency to get emotionally involved on the level of Engagement and of the tendency to get absorbed (by blocking our external distractors) on Spatial Presence.

The personality factor extraversion was found to have a positive effect on the level of Engagement. Those participants who rated high on extraversion experienced systematically higher levels of emotional Engagement than those who rated low. A significant relation between Spatial Presence and Neuroticism also emerged. Those participants who scored high on neuroticism reported systematically higher levels of Spatial Presence than those who scored low on this trait.

\subsection{Introducing interactions between immersive components and individuals' characteristics}

In the last stage of the study we look for possible heterogeneities in the impacts of BA and SE on the quality and Presence measures based on individual characteristics. That is, we explore 
whether the impact of excluding BA or SE had a different magnitude across different groups of participants based on their characteristics. We introduce such heterogeneity in our model through a set of interaction terms between the dummy variables describing the absence of $\mathrm{BA} / \mathrm{SE}$ in the experiment and the participants' characteristics collected in our study.

After extensive testing, it emerged that the absence of BA generated different effects on the perceived QoE, QoC and QoI and on the levels of Spatial Presence and Engagement across different groups of participants. We also found that the absence of SE produced different effects on the perceived Quality of Image across groups with different levels of conscientiousness. No significant interactions were found for the perceived Quality of Audio or Sensory Effects (see Table 14).

We found that the effect on the Quality of Experience of the absence of BA is influenced by individual's preferences in relation to the content and by the level of conscientiousness. That is, the variation on QoE valuations resulting from the exclusion of BA was different for the groups of fans and non-fans. Differences in marginal effects of BA between football fans and non-fans reveal that whereas the absence of BA does not affect the perceived Quality of Experience for football fans, it generates a significant drop for non-fans. In a similar way we found differences in marginal effects across different groups based on their levels of conscientiousness. We found that the absence of BA only generates a significant drop in the QoE for those individuals who scored high on conscientiousness.

We also found that the impact on the Quality of Experience and of Content of excluding BA from the experimental condition is influenced by the level of agreableness. Differences in marginal effects across different groups based on their levels of agreeableness show that the absence of BA only generates a significant drop in the QoE and in the QoC for those participants who scored high on this personality trait.

The variation on participants' valuations of the Quality of Image resulting from the exclusion of BA was different across groups with different levels of emotional involvement, conscientiousness and openness to experience. In a similar way, the impact on the perceived Quality of Image of the absence of SE was different across groups with different levels of conscientiousness. Differences in marginal effects of BA and of SE across groups based on their levels of conscientiousness reveal that the absence of BA or the absence of SE only generate a significant drop in the perceived QoI for those participants who scored high on conscientiousness. Conversely, differences in marginal effects of BA across different groups based on their levels of emotional involvement reveal that the absence of BA only generates a significant drop in the perceived QoI for those individuals who scored low on the tendency to get emotionally involved. A similar analysis across groups with different levels of openness to experience reveal that the absence of BA only generates a significant drop in the perceived QoI for those participants who scored low in openness.

As regards to the dimensions of Presence, we found that the absence of BA generates different effects on the perceived levels of Spatial Presence and Engagement across different groups of participants based on their tendency to get emotionally involved. Differences in marginal effects of BA across these groups reveal that whereas the absence of BA does not affect the level of Spatial Presence for participants with medium or high scores in the tendency to get emotionally involved, it generates a significant drop for those who scored low on this personality factor. Similarly, differences in marginal effects of BA across the same groups reveal that whereas the absence of BA does not affect the perceived level of Engagement for participants with medium or high levels of tendency to get emotionally involved, it generates a significant drop for those who scored low on this personality factor. That is, the level of Engagement experienced by those individuals who are less prone to get emotionally involved drops significantly with the exclusion of binaural audio from the experimental condition. 


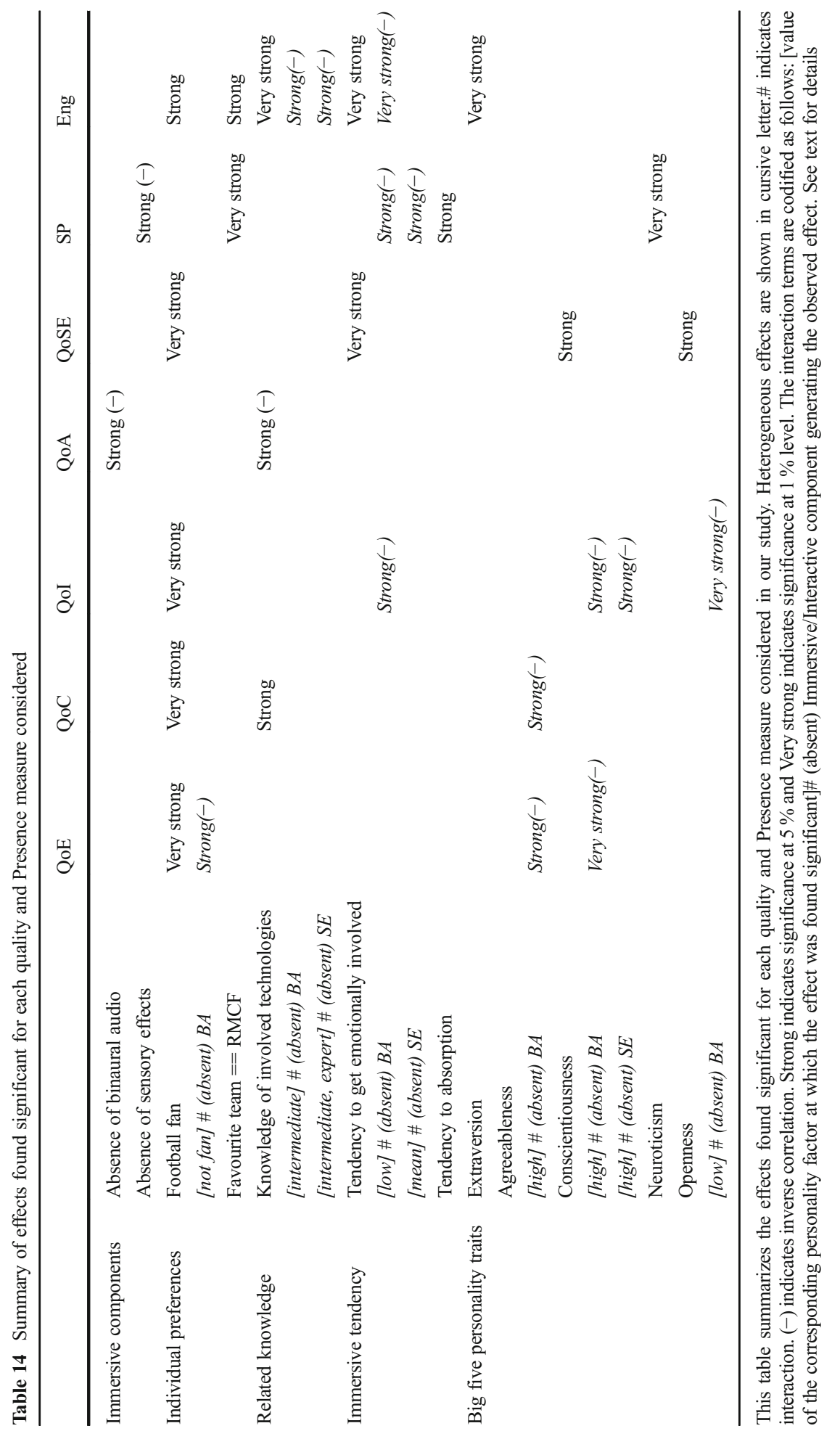




\section{Discussion}

The objective of this research is to gain insight into the impact of binaural audio and sensory (light and olfactory) effects on the sports media experience, both at the overall level (average effect) and as a function of users' characteristics (heterogeneous effects).

In our experimental study three experimental conditions were defined, one baseline condition and two treatment conditions. In the baseline condition participants were exposed to both sensory effects and binaural audio. In the treatment conditions participants were exposed to one of the immersive components (i.e. BA or SE). To address our first goal (i.e. to reveal the average effect of the immersive elements binaural audio and sensory effects on the dependent measures), we fit a base model. The model estimates the impact of the exclusion of BA and of SE on the quality and Presence measures considered by comparing the scores assigned by the participants to these measures in the corresponding treatment condition with respect to the baseline group. Our second objective was addressed in two steps. First, we looked for systematic differences in the dependent measures (i.e. the perceived Quality of the Experience and of its components and the dimensions of Presence) associated to each participant's characteristic. And finally, we interacted the immersive elements BA and SE with the personal characteristics observed to reveal whether these have or not a modulating effect on the perceived impact of BA or SE.

Our base models did not reveal any significant variation on the dependent variables - except for the perceived Quality of Audio- as a result of excluding binaural audio or sensory effects from the experimental condition. By considering solely the absence of binaural audio and of sensory effects as independent variables, our base models were not able to explain the variance neither in the QoE, QoC, QoI or QoSE, nor in the Presence measures. In other words, the exclusion of binaural audio or of sensory effects from the experimental condition did not generate, on average, significantly different valuations for these dependent measures in comparison to those in the baseline group (where both BA and SE were present).

However, after incorporating the user factors observed in our experiment the explicative power of our models increased significantly. As could be expected considering the subjective nature of the media experience, individual differences (in terms of the observed features) explained most of the variation in the perceived Quality of the Experience and of the media components and on the levels of Spatial Presence and Engagement. Furthermore, by controlling for the effect of individuals' characteristics on the dependent variables, new effects (masked in the previous models) were disclosed. Table 14 summarizes the effects found significant for each quality and Presence measure considered.

As shown, our first hypothesis does not hold as regards to the speculated average effect of binaural audio on the Quality of Experience and on the dimensions of Presence. Instead, a straightforward effect of binaural audio on the perceived Quality of Audio emerged. A significant proportion of the variation in the QoA was explained by the exclusion of binaural audio from the experimental condition. The parameter estimates for this component are in line with a priori expectations (i.e. negative) and imply that respondents preferred binaural audio over standard stereo audio. The knowledge of involved technologies accounted for almost the other half of the explained variance in the QoA. Technology knowledgeable participants were more critical about the Quality of Audio than those with less technological knowledge. This is probably because those participants with high knowledge (and presumably also high interest) about technology paid a lot of attention to the implementation details. In consequence, as suggested by previous works (e.g. [28, 41,66], they could be more prone to detect technical errors than not experts. The higher level of Engagement experienced by these individuals in 
comparison to the one experienced by those with less technological knowledge could be also given by their higher enthusiasm in relation to the technological innovations integrated in our setup. The assumption that technology-knowledgeable participants deviated their attention away from the content might also explain why these users were more benevolent in the content quality valuations than their counterparts. In this sense, a poor attention might be behind the omission of content-related problems.

The absence of binaural audio was found to have also a heterogeneous effect on the overall Quality of Experience, on the perceived qualities of content and image and on the experienced levels of Spatial Presence and Engagement. The magnitude of these effects was modulated by different users' characteristics, which include: individual preferences in relation to the content, tendency to get emotionally involved, agreeableness, conscientiousness and openness to experience.

The impact of the absence of binaural audio on the QoE was different across the groups of football fans and non-fans (see H2a.). Whereas the absence of binaural audio does not affect the perceived QoE for football fans, it generates a significant drop for non-fans. In other words, non-fans' judgment on the overall Quality of Experience is more sensitive to a drop in the audio quality than football fans' valuations. However, considering that both fans and non-fans preferred binaural audio over standard stereo audio, we can argue that this differentiated effect on the QoE is not given by differences in the perceived audio quality between these groups. Instead, we hypothesize that the impact of binaural audio on the QoE reported by non-fans emerges partially from a higher importance of this media component in non-fans' experience in comparison to the relative importance perceived by football fans. As suggested by previous findings (see discussion in [98]), the impact of a given media component on the user experience is modulated by the relative importance of the sensory modality addressed by such component during the media use. In our experiment, probably non-fans relied considerably on the comments and explanations provided by the commentator and on the audio events (i.e. acclaims, applauses, boos, blows of whistle) to follow the evolution of the game events displayed. As football fans watch football games frequently (see Section 3.5), they are expected to count on more trained attentional and cognitive skills than non-fans as regards to the use of this media genre. In consequence, they are probably more efficient than non-fans on integrating a wide amount of information coming from different sensory inputs and on interpreting and contextualizing the resulting stimulus. Thus, for these individuals, other criteria as the amount, accuracy, singularity or complementarity of the information obtained through each modality could prevail when it comes to assessing the relevance of each sensory input. Additionally, the higher level of emotional Engagement experienced by football fans in comparison to non-fans suggests that for these individuals the experience is highly modulated by emotional processes. In contrast, judging by the direct impact of the perceived audio quality on the overall Quality of Experience reported by non-fans, cognitive processes (and in particular those related to quality judgment) seem to be at the core of these subjects' experience.

The impact of the absence of binaural audio on the Quality of Experience was found to be different across groups of participants with different levels of conscientiousness. The exclusion of binaural audio from the experimental condition only generated a significant drop in the perceived QoE for those individuals who scored high on conscientiousness. A high value of conscientiousness is usually associated to reflexive, organized, hard-working and reliable persons [5, 40], as well as with an increased perceptual sensitivity [63]. Thus, a possible interpretation of the impact of this trait may be that participants who scored high on conscientiousness were more sensitive to the influence of sensory effects and were more consistent on their valuations than those who scored low on this personality factor. 
The variation on participants' valuations of the Quality of Content resulting from the exclusion of binaural audio from the experimental condition was different across groups of individuals based on their level of agreeableness. The absence of binaural audio only generates a significant drop in the perceived QoC for those participants who scored high on agreeableness. A high value of agreeableness is usually related to trustful, helpful, altruist, tender-minded and modest persons. As suggested by Sacau et al. [65], this trait could have a significant role on the suspension of disbelief, which is also considered to favour media enjoyment [92].

In line with previous results, we found a cross-modal influence of binaural audio on the perceived Quality of Image. However, the effect is not homogeneous. Instead, the exclusion of binaural audio from the experimental condition produced different effects on the perceived QoI across groups of participants with different levels of tendency to emotional involvement, conscientiousness and openness to experience. The absence of binaural audio generated a significant drop in the perceived QoI for those individuals who scored high on conscientiousness, low in the tendency to get emotionally involved or low in openness to experience. Again, those individuals who scored high on conscientiousness were found to be more sensitive to the impact of this immersive component (i.e. binaural audio) than those who scored low on this trait. Besides, as in non-fans' experience, audio seems to play a very important role for those individuals who are less open to new experiences and/or less prone to get emotionally involved with media.

In a similar fashion, the effect on the levels of Spatial Presence and Engagement of the absence of binaural audio was found to be influenced by individuals' tendency to get emotionally involved. Whereas the absence of binaural audio does not affect the perceived levels of Spatial Presence and Engagement for participants with intermediate or high levels of tendency to emotional involvement, it generates a significant drop for those who scored low on this personality factor. This suggests that binaural audio may have the potential to activate emotional and cognitive mechanisms that do not appear or that emerge with less frequency in these individuals, in comparison to those with intermediate or high tendency to get emotional involved. In particular, it seems to favour those mechanisms leading to an increased emotional reaction towards media and to the suspension of disbelief that underlines the elicitation of Presence. From a different perspective, this result suggests that binaural audio could be used to enhance the levels of Spatial Presence and emotional Engagement experienced by those individuals who are less prone to get emotionally involved with media, and the resulting enjoyment of the media experience. Interestingly, the impact of the absence of binaural audio on the level of Engagement was found to be influenced also by the level of technological knowledge. The level of Engagement experienced by those individuals with intermediate knowledge of the involved technologies dropped significantly with the exclusion of binaural audio from the experimental configuration.

In contrast to the more generalized impact of binaural audio on the quality and Presence measures considered, the influence of sensory effects concentrates mainly on the dimensions of Presence. In partial support of our first hypothesis, the absence of sensory effects was found to produce a negative impact on the level of Spatial Presence. In other words, those participants who were randomly allocated to the groups where sensory effects were not administered experienced, on average, lower levels of Spatial Presence than those in the groups where sensory effects were present. As discussed in Section 2, multi-sensorial media is expected to deliver more immersive experiences than a traditional media asset. In our experiment, the main audiovisual content is complemented by a meaningful combination of sensory effects, which are rendered in response to specific game events. This approach, in combination with the physical configuration of our testbed, addresses the four dimensions of immersion by: isolating the physical reality through ambient lighting effects (inclusion); stimulating a broader set of sensory modalities, including smell (extensiveness); rendering 
effects that physically surround the user (surrounding); and, ensuring a correct delivery of such effects in terms of spatio-temporal resolution and fidelity (vividness). Thus, considering the wellknown relation between immersion and Presence, it is not a surprise that those individuals who were assigned to the groups in which sensory effects were administered reported higher levels of Spatial Presence than those who were not exposed to the component. Additionally, an heterogeneous impact of sensory effects on Spatial Presence across groups of individuals with different levels of tendency to get emotionally involved was revealed. Whereas the level of Spatial Presence experienced by those individuals who scored low or high on the tendency to get emotionally involved is not affected by the exclusion of sensory effects from the experimental configuration, it drops significantly for those individuals with scores around the sample average. In other words, sensory effects increased significantly the level of Spatial Presence experienced by those individuals with average tendency to get emotionally involved. In contrast, the sense of physical transportation reported by those who scored high or low on this trait was not affected by the absence of this component. Also, participants with intermediate or high knowledge of involved technologies felt systematically more engaged in the media experience when sensory effects were administered in comparison to the conditions in which the component was not present. Thus, technologyenthusiastic users may feel engaged in the experience via their interest towards the technological innovations associated to this component.

We found also an impact of sensory effects on the Quality of Image. The magnitude of this effect was different across groups of participants with different levels of conscientiousness. This outcome supports previous results revealing a significant impact of wind, vibration and light and olfactory effects on the perceived quality and sense of reality of video, respectively $[25,94]$. As for binaural audio, a cross modal impact (i.e. of sensory effects on the perceived quality of image) emerges in the experience of highly conscious individuals, who seem to be more sensitive to the presence of sensory effects and more consistent on the related quality valuations than those who scored low on this trait.

Our analysis revealed also a direct impact on the user experience of some of the personal characteristics collected in our experiment. We found a generalized influence of individual preferences in relation to the content on most of the quality and Presence measures considered. Football fans systematically assigned higher quality valuations to the Content, Image and Sensory Effects and reported higher levels of emotional Engagement than non-fans. Taken together, these outcomes suggest that, in the context of a multi-sensorial media experience, quality judgment is modulated by the level of personal preferences in relation to the content. This effect is not limited, as could be expected, to the perceived Quality of Content or to the overall Quality of Experience. Instead, our dataset reveals a significant impact of individual preferences on the perceived Quality of other media components as Image and Sensory Effects. These results are in coherence with previous findings highlighting the influence of factors as personal relevance of the content and domain-specific interest and their role on controlled attention allocation $[41,49,66,101]$.

Those who favoured the winner team experienced systematically higher levels of emotional involvement than those who favoured other teams. Team preferences were found to have also a significant influence on the level of Spatial Presence. These outcomes are in coherence with the impact on Presence of cognitive factors as empathy towards an entity or character in the story [67], or of identification [20], defined as "an imaginative experience in which a person surrenders consciousness of his own identity and experiences the world through someone else's point of view" [14]. In our study, as pointed out by Decock et al., identification could lead to the temporary adoption of the favoured team's point of view and to viewing the world 
through its role in the game. Thus, resulting in enhanced senses of Spatial Presence and emotional Engagement. We did not find, however, any significant influence of team preference on quality valuations, which reinforce the validity of the Spatial Presence and Engagement constructs as global measures to explain the emotional dimension of a media experience.

Those individuals with higher tendency to get emotionally involved were more prone to valuate high the Quality of Sensory Effects than those with lower tendency. Previous findings on the influence of human senses on emotions suggest that olfactory effects have the potential to recall personal memories and related emotions in a highly vivid and strong manner [31, 58, 100, 103]. Our results suggest that sensory effects are better appreciated by those individuals who have high tendency to get emotionally involved with media in comparison to those who score low on this factor. Thus supporting the hypothesized effect of this immersive component on the cognitiveaffective assessment of the media experience. The Quality of Sensory Effects was also influenced significantly by two personality traits, namely conscientiousness and openness to experience. A high value of conscientiousness is usually associated to reflexive, organized, hard-working and reliable persons [5, 40], as well as with an increased perceptual sensitivity [63]. Thus, a possible interpretation of the impact of this trait may be that those participants who scored high on conscientiousness were more sensitive to the influence of sensory effects and were more careful of providing consistent valuations than those who scored low on this trait. The fact that this effect emerges in the valuations of sensory effects and not in those provided for the other quality measures could be explained by the innovative character of this immersive component. Unlike binaural audio, which delivers an increased quality of a component traditionally present in the media experience, sensory effects introduce a completely new effect. We hypothesize that the users notice the presence of this immersive element and in consequence, build a quality judgment about it in a more objective and focused way (in particular highly conscientious individuals). The personality trait openness to experience describes to what extent an individual is receptive to new ideas and approaches. Given the innovative effect introduced by sensory effects, it seems quite coherent that those participants who rated high on openness to experience assigned higher valuations to this component than those who rated low on the trait.

In line with previous results and a-priori expectations are also the positive impact of the tendency to get emotionally involved on Engagement and the effect of the tendency to get absorbed on Spatial Presence (see for instance [2, 67]).

The personality factor extraversion was found to have a positive effect on the level of Engagement. Those participants who rated high on extraversion experienced systematically higher levels of emotional Engagement than those who rated low. Highly extroverted individuals are usually sociable, active, assertive, outgoing and emotionally positive. It seems that these attributes contribute to a positive emotional appraisal of the media experience. Our evidence could not support, however, the relation between extraversion and Spatial Presence found by Laarni et al. [44]. In contrast to their outcomes and to those of Weibel et al. [97], we did find a significant relation between Spatial Presence and Neuroticism. Those participants who scored high on neuroticism reported systematically higher levels of Spatial Presence than those who scored low on this trait.

\section{Conclusions and future work}

This paper has explored the impact of binaural audio and sensory effects on the sports media experience, both at the overall level (average effect) and as a function of users' characteristics (heterogeneous effects). At the overall level, our experimental study revealed that participants 
preferred binaural audio over standard stereo audio and that sensory effects increase significantly the level of Spatial Presence.

The increased audio quality enabled by binaural audio was found to have also a heterogeneous impact on the QoE, QoC and QoI and on the levels of Spatial Presence and Engagement. The magnitude of these effects was found to be modulated by personal characteristics as individuals' preferences in relation to the content, tendency to emotional involvement and levels of agreeableness, conscientiousness and openness to experience. In general, non-fans and those participants who scored low on the tendency to get emotionally involved and openness to experience and high on agreeableness and conscientiousness seem to be more sensitive to the presence of this immersive component. Differences across groups of participants based on the former three factors seem to be given by a higher importance of audio in the experience of non-fans and of those individuals who are less open to new experiences and/or less prone to get emotionally involved in comparison to the relative importance perceived by their counterparts. Conscientiousness and agreeableness-based differences could be explained by the increased perceptual sensitivity attributed to those individuals who scored high on conscientiousness and by the role of agreeableness on the suspension of disbelief and thus, on media enjoyment. These outcomes lead to a possible research path focused on exploring the potential of binaural audio to enhance the media experience of these individuals.

The outcomes concerning the impact of sensory effects on the media experience were below our expectations. Sensory effects were found to have a dual impact on Spatial Presence and heterogeneous effects on Engagement and on the perceived Quality of Image. The presence of sensory effects increased significantly the sense of physical transportation (average effect). Additionally, those individuals who scored around average on the tendency to get emotionally involved resulted to be particularly sensitive to this effect. Also, technology knowledgeable participants felt systematically more engaged with the media experience when sensory effects were administered in comparison to the conditions in which the component was not present. Thus, we hypothesize that these users may feel engaged via their interest towards the technological innovations associated to this immersive component. Furthermore, our study revealed a cross-modal impact of sensory effects on image for those participants who scored high on conscientiousness. Taken together, our results suggest that binaural audio and sensory effects could be powerful tools to enhance the user experience with media, with emphasis on its emotional dimension. In the future we will further analyze the impact on the user experience of stimulating a single sensory input (i.e. using only light or olfactory effects) and of different combinations and alternative (user-centered) designs of these effects. Several sources of inspiration can be found in literature to this respect (e.g. [58]).

The personal characteristics collected in our experiment explained most of the variation in the dependent variables, confirming the usually neglected role of individual differences on the media experience. Preferences in relation to the content, knowledge of involved technologies, tendency to emotional involvement and conscientiousness were among the user variables with the most generalized influence. In particular, the former two features seem to present a conflict in the allocation of attentional resources towards the media content versus the technical features of the system, respectively. Additionally, football fans' experience seems to be modulated by emotional processes whereas for non-fans cognitive processes (and in particular those related to quality judgment) prevail. In this sense, our results reinforce the validity of the Spatial Presence and Engagement constructs as global measures to explain the emotional dimension of a media experience.

The limitations of this work should be acknowledged. Its scope is framed by the media genre (i.e. sports - football) and by the limited resources of the research project that promoted it, which translates into a limited duration of experiments and into content and sample (e.g. size and 
composition) constraints. Whereas our sample was almost perfectly balanced in terms of preferences and habits in relation to the sports media content, it was quite biased when it comes to teams preference. In particular, those individuals that favoured FCB were scarcely represented. Thus, some of our outcomes might not be valid for this group. Furthermore, the "mixed" design adopted was expected to contribute to the statistical soundness of our results by combining the advantages of the within-subjects (greater statistical power, fewer subjects needed) and betweensubjects (lower threats to internal validity) approches. However, this configuration led also to an increased complexity of the statistical analysis, resulting in an uncertain cost-effectiveness. One of the main issues raised in relation to this experimental design is the possible difference between the groups assigned to the different experimental configurations. Although our analysis did not reveal any significant difference between the three groups, these may be different in other ways not measured in the study. In that case, alternative statistical methods (i.e. different from OLS) shall be applied. Also, individual interviews, focus groups and/or other qualitative methods would have been very helpful to interpret some statistical results and draw conclusions.

Nevertheless, our work has contributed empirical findings that are worthy of further study. These results are expected to contribute to the creation of a research framework from which strong causal assumptions could be derived. In particular, they could support the formulation of specific hypotheses addressing the potential of binaural audio and light and olfactory effects to enhance the sports media experience of different user segments as a function of their characteristics. At this point, Structural Equation Modelling could be applied to propose, for instance, a Technology Acceptance Model. Furthermore, the "inverse" experimental design adopted -based on the exclusion of the immersive components analyzed with respect to the baseline scenario- could be a promising approach to avoid the pitfalls and biases of departing from a technological constrained scenario where any improvement can be perceived too optimistically. From a market perspective, our results highlight the importance of a detailed characterization of the target audience segments to enable a successful deployment of immersive media. Thus, the collection of individual data and its further analysis, integration and use -in a privacy-respectful framework- for the provision of personalized immersive media experiences seems a very promising avenue for further research in this field.

Acknowledgments The work presented in this manuscript was developed partially within the ImmersiveTV project. The authors would like to thank the Spanish Ministry of Industry Tourism and Commerce for its support through the funded project TSI-020302-2010-61.

\section{Appendix 1 Measuring instruments and factors}

The measures gathered during the experiments are summarized as follows (scales in brackets). In the case of direct scores the question asked is included preceded by a $\mathrm{Q}$.

Inclusion criteria

1. Screening for (corrected to-) normal visual acuity and stereopsis:

a. Snellen Chart: screening for normal visual acuity

b. self-developed materials based on Annex 1 of ITU-R Recommendation BT.1438 [35]: screening for normal stereopsis 
2. BDI-II - Beck Depression Inventory [3]: The BDI_Score was computed from the answers of each participant to the questionnaire [1-10: normal; 11-16: mild mood disturbance; 17-20: borderline clinical depression; 21-30: moderate depression; 3140: severe depression; over 40: extreme depression]

Personal characteristics

3. Previous knowledge of the involved technologies:

a. KTech. [1: none; 2: basic; 3: intermediate; 4: expert]; Q. How would you rate your current level of knowledge on video, audio or home automation technologies?

4. Preferences and habits in relation to the content:

a. Lfoot [5-point Likert scale from 1: not at all to 5: very much]; Q. How much do you like football?

b. Fview [5-point Likert scale from 1: never to 5: almost always]; Q. How frequently do you watch football matches?

c. FFT [1: RMCF; 2: FCB; 3: Other; 4: None]; Q. Please select from the following options the one that includes the football team of your preference. If you do not have a preferred team, please select option 4.

5. ITQ measures: Immersive Tendency - ITQ questionnaire [102]. The following factors were computed from the answers of each individual to the ITQ questionnaire as described in [97]:

a. ITQ_Emot. Emotional involvement [continuous scale from 1 to 7]; it refers to the tendency to get emotionally involved. It is related to the degree of emotional reaction (either positive or negative) toward media exposure [97]

b. ITQ_Absor. Absorption [continuous scale from 1 to 7]; it refers to the tendency to become absorbed in / focus attention on an activity. It is related to the capability of an individual to concentrate and block out external and distracting stimuli [97].

6. BFI Measures: Personality traits - Big Five Questionnaire [5, 38, 39]: The following factors were computed from the answers of each individual to the questionnaire (see [40] for a comprehensive definition):

a. BFI_Extrav. Extraversion [continuous scale from 1 to 5]; it implies an energetic approach toward the social and material world. That is, it measures to what extent an individual is oriented toward the external world (the opposite to introvert). In this sense, it includes traits such as sociable, active, assertive, outgoing and emotionally positive

b. BFI_Agr. Agreeableness [continuous scale from 1 to 5]; it contrasts a prosocial and communal orientation towards others with antagonism. Agreeable persons can be generally described as trustful, helpful, altruist, tender-minded and modest

c. BFI_Cons. Conscientiousness [continuous scale from 1 to 5]; it describes socially prescribed impulse control that facilitates task-and goal-directed behavior. It is generally associated with individuals that that tend to think before acting, perform well following norms and rules, planning, organizing and prioritizing tasks and that are hard-working, reliable, organized and self-disciplined. The trait has been also related to an increased perceptual sensitivity [63]. 
d. BFI_Neurot. Neuroticism [continuous scale from 1 to 5]; it contrasts emotional stability and even-temperedness (low scores) with negative emotionality, such as feeling anxious, nervous, sad, and tense (high scores). People scoring high on neuroticism are usually nervous, insecure, anxious, vulnerable and excitable

e. BFI_Open. Openness to experience (vs. closed-mindedness) [continuous scale from 1 to 5]; it describes the breadth, depth, originality, and complexity of an individual's mental and experiential life. This factor is related to personality traits as adventurous, liberal, imaginative, receptive to new ideas and approaches and having a preference for variety Presence and quality measures

7. ITC-SOPI measures: Presence dimensions - ITC-SOPI Questionnaire [48]. The following factors were computed from the answers of each participant to the questionnaire:

a. SP. Spatial Presence [continuous scale from 1 to 5]; it refers to a sense of physical placement in the mediated environment and of interaction with and control over parts of the mediated environment

b. Eng. Engagement [continuous scale from 1 to 5]; it refers to the feeling of psychological involvement and of enjoying the content

8. Quality measures - Quality assessment questionnaire (self-developed). Subjective quality assessment of each independent stimuli/component and of the overall QoE [11-point Likert scale from 0: extremely bad to 10: excellent]. We provide aclaratory notes associated to each quality measure on the specific issues encompassed by the component to be valuated, as follows:

a. QoC. Quality of Content as perceived by the user. It encompassess issues as the plot and the specific sequence of game events;

b. QoI. Quality of Image as perceived by the user. It encompassess issues as the image resolution, luminance, color, sharpness, contrast and depth;

c. QoA. Quality of Audio as perceived by the user. It encompassess issues as the audio clarity, naturalness, richness, sharpness and smoothness;

d. QoSE (only rated when $\mathrm{SE}=1$ ). Quality of Sensory Effects as perceivd by the user. It encompassess issues as the naturalness, richness and complementarity (to the sports media content) of sensory effects;

e. QoE. Overall Quality of Experience as perceived by the user. It refers to the global quality of the media experience (encompassing all the components presented).

\section{Appendix 2. Recruiting e-mail}

The participants were recruited via e-mail. We e-mailed our collegaues at several research centers and departments at the Technical University of Madrid asking for volunteers to participate in the experiment. We raffled off a Tablet PC among all the participants as incentive. The recruiting e-mail reads as follows:

Dear colleague,

During the last two years our VR Group at CeDInt has collaborated with other entities in a R\&D project called 'ImmersiveTV'. The project focuses on the creation of new immersive and 
interactive solutions aimed at complementing the media content with meaningful effects and/or functionalities.

The ImmersiveTV consortium has implemented an experimental setup integrating some of the immersive components considered in the project. Now we focus our efforts on analyzing the potential effect (either positive or negative, if any) of these components on the user experience. To that end we have designed a user experiment aimed at revealing how these components are perceived by the user in the light of his/her personal characteristics.

xThe purpose of this e-mail is to ask for volunteers to participate in the study. The experiment will take place in the 'Demos' Lab during the next two weeks. Volunteers will be exposed to the 'enhanced' media content and will be asked to valuate the experience on an individual basis according to his/her perception of it.

Should you be able to participate please contact me for further details on next steps.

Thank you in advance for your collaboration.

Best regards,

The ImmersiveTV team.

PS: A Tablet PC will be raffled off among all the participants in the experiment.

\section{Appendix 3 Explanation Given To Participants Before The Experiment}

In the laboratory, before initiating the experiment, we explained the general goals of the experiment and the procedure to be followed, as follows:

Goals:

The goal of this experiment is to analyze the potential effect (either positive or negative, if any) of a set of sensory effects on the user experience with media. In particular, we aim to study how these sensory effects are perceived by the user in the light of his/her individual characteristics. Therefore, this experiment is not intended to validate the specific solution implemented in our test bed but to inform future research and development works on the use of sensory effects to complement media content.

Procedure:

The experiment comprises two sessions in which you will watch a report of the first and second parts of a football match between the F.C. Barcelona and Real Madrid C.F. At each session, different sensory effects can be activated. We do not expect you to be particularly alert to these effects. On the contrary, we would ask you to relax and enjoy the experience as you would do in your living room.

After each session you will be asked to report on the experience using a questionnaire. Considering the previously mentioned goals we would like to ask you to be as faithful as possible to your individual perception of the experience in your answers to these questionnaires.

After this explanation, the participant was invited to formulate any question he/she may have and the issues raised were clarified at the same "general" level (i.e. without revealing further details on the content or the specific sensory effects introduced). 


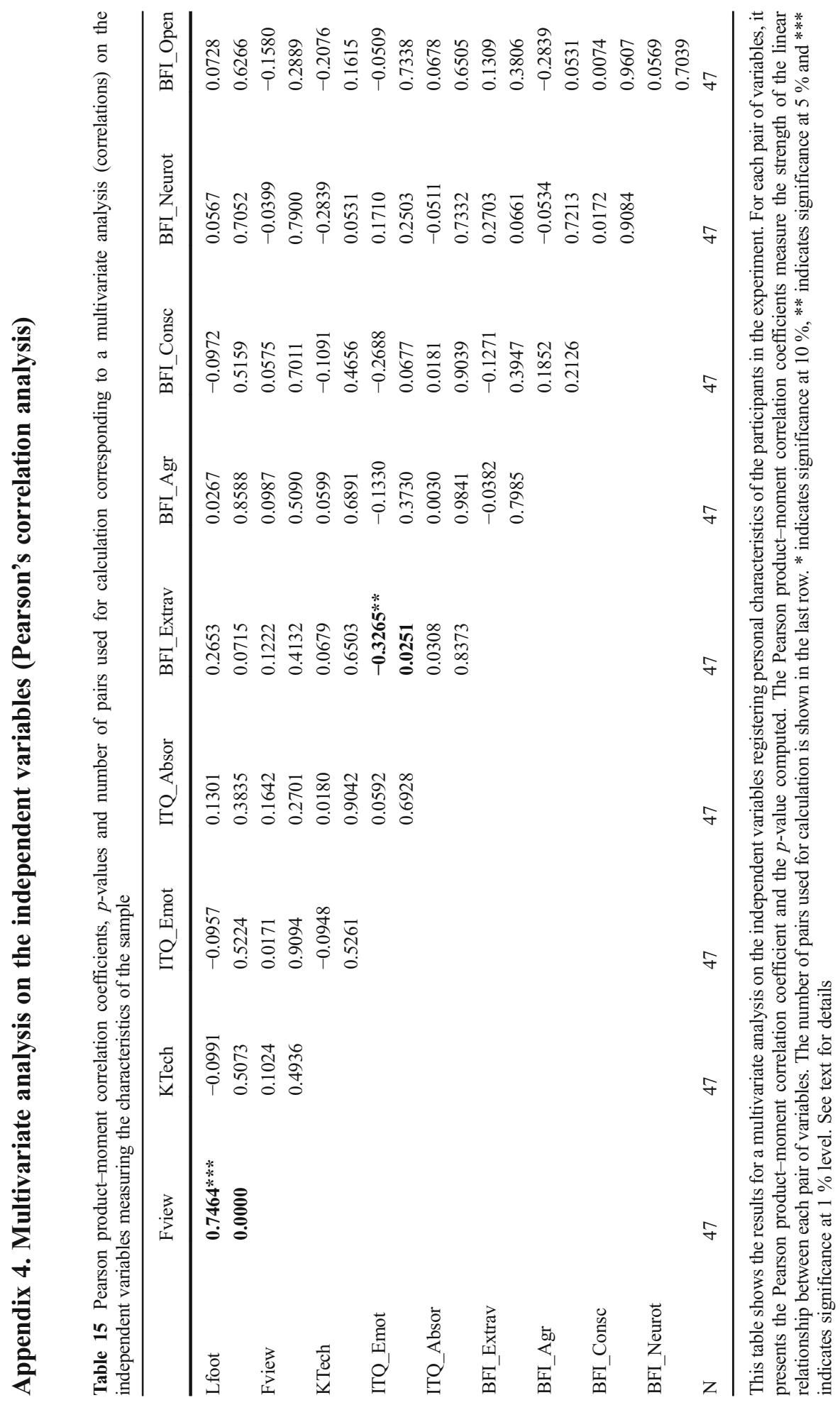


1. Alsina-Jurnet I, Gutierrez-Maldonado J (2010) Influence of personality and individual abilities on the sense of presence experienced in anxiety triggering virtual environments. Int J Hum Comput Stud 68:788-801

2. Baños R, Botella C, García-Palacios A et al (1999) Psychological variables and reality judgment in virtual environments: the roles of absorption and dissociation. CyberPsychology Behav 2:143-148. doi:10.1089/ cpb.1999.2.143

3. Beck AT (1961) An inventory for measuring depression. Arch Gen Psychiatry 4:561. doi:10.1001/ archpsyc.1961.01710120031004

4. Beerends JG, De Caluwe FE (1999) The influence of video quality on perceived audio quality and vice versa. J Audio Eng Soc 47:355-362

5. Benet-Martínez V, John OP (1998) Los Cinco Grandes across cultures and ethnic groups: multitrait multimethod analyses of the Big Five in Spanish and English. J Pers Soc Psychol 75:729-750

6. Bey C, McAdams S (2002) Schema-based processing in auditory scene analysis. Percept Psychophys 64: 844-854

7. Bleumers L, Lievens B, Pierson J (2011) From sensory dream to television format: gathering user feedback on the use and experience of omnidirectional video-based solutions. ISPR 2011 Int. Soc. Presence Res. Annu. Conf

8. Bowman DA, McMahan RP (2007) Virtual reality: how much immersion is enough? Computer 40:36-43. doi:10.1109/MC.2007.257

9. Box GEP, Draper NR (1987) Empirical model-building and response surfaces. Wiley, New York

10. Box GEP, Hunter JS, Hunter WG (2005) Statistics for experimenters: design, innovation, and discovery, 2nd edn. Wiley, New Jersey

11. Bracken C, Pettey G, Wu M (2011) Telepresence and attention: secondary task reaction time and media form. Proc. Int. Soc. Presence

12. Chandrasekaran C, Ghazanfar AA (2011) When what you see is not what you hear. Nat Neurosci 14:675676. doi: $10.1038 / \mathrm{nn} .2843$

13. Coen M (2001) Multimodal integration-a biological view. Proc. Fifteenth Int. Jt. Conf. Artif. Intell. Seattle, WA, pp 1417-1424

14. Cohen J (2001) Defining identification: a theoretical look at the identification of audiences with media characters. Mass Commun Soc 4:245-264. doi:10.1207/S15327825MCS0403

15. Cui LC (2003) Do experts and naive observers judge printing quality differently? In: Miyake Y, Rasmussen DR (eds) Electron. Imaging 2004. International Society for Optics and Photonics, pp 132-145

16. Curran T, Gibson L, Horne JH et al (2009) Expert image analysts show enhanced visual processing in change detection. Psychon Bull Rev 16:390-397. doi:10.3758/PBR.16.2.390

17. Darken RP, Bernatovich D, Lawson JP, Peterson B (1999) Quantitative measures of presence in virtual environments: the roles of attention and spatial comprehension. Cyberpsychol Behav 2:337-347

18. de Kort YAW, Ijsselsteijn WA, Kooijman J, Schuurmans Y (2003) Virtual laboratories: comparability of real and virtual environments for environmental psychology. Presence Teleoperators Virtual Environ 12: 360-373

19. de Ruyter B, Aarts E (2004) Ambient intelligence: visualizing the future. Proc. Work. Conf. Adv. Vis. interfaces - AVI'04. ACM Press, New York, p 203

20. Decock J, Looy J Van, Bleumers L, Bekaert P (2011) The pleasure of being (there?). An Explorative study into the effects of presence and identification on the enjoyment of an interactive theatrical performance using Omni- Directional Video. ISPR 2011 Int. Soc. Presence Res. Annu. Conf

21. Eagly AH, Chaiken S (1995) The psychology of attitudes. Psychol Mark 12:459-466. doi:10.1002/mar. 4220120509

22. Eagly AH, Chaiken S (1998) Attitude Structure and Function. In: Gilbert DT, Fiske, ST \& Lindzey G (eds) Handbook of Social Psychology. McGraw-Hill, New York, pp 269-322. ISBN: 0195213769, 9780195213768

23. Emoto M, Nojiri Y, Okano F (2004) Changes in fusional vergence limit and its hysteresis after viewing stereoscopic TV. Displays 25:67-76. doi:10.1016/j.displa.2004.07.001

24. Galloso I, Feijóo C, Santamaría A (2015) Novel approaches to immersive media: from enlarged field-ofview to multi-sensorial experiences. In: Kondoz A, Dagiuklas T (eds) Nov. 3D Media Technol. Springer, New York, pp 9-24

25. Ghinea G, Ademoye O (2012) The sweet smell of success: enhancing multimedia applications with olfaction. ACM Trans Multimed Comput Commun Appl 8:1-17. doi:10.1145/2071396.2071398

26. Goldstein EB (2010) Sensation and perception, 8th ed. Cengage Learning, 2009, Belmont, CA

27. Hands DS (2004) A basic multimedia quality model. IEEE Trans Multimedia 6:806-816. doi:10.1109/ TMM.2004.837233 
28. Hands DS, Brotherton MD, Bourret A, Bayart D (2005) Subjective quality assessment for objective quality model development. Electron Lett 41:408. doi:10.1049/el:20058339

29. Hasebe H, Oyamada H, Ukai K et al (1996) Changes in oculomotor functions before and after loading of a 3-D visually-guided task by using a head-mounted display. Ergonomics 39:1330-1343. doi:10.1080/ 00140139608964553

30. Hendrix C, Barfield W (1995) Presence in virtual environments as a function of visual and auditory cues. Virtual Real Annu Int Symp 1995 Proceedings 74-82. doi:10.1109/VRAIS.1995.512482

31. Herz RS, Engen T (1996) Odor memory: review and analysis. Psychon Bull Rev 3:300-313. doi:10.3758/ BF03210754

32. Hogg MA, Vaughan G (2005) Social psychology, 4th edn. Prentice-Hall, London

33. IJsselsteijn W (2000) Presence: concept, determinants, and measurement. Proc. SPIE. Spie, pp 520-529

34. ISO/IEC (2013) Information technology - media context and control - part 3: sensory information (ISO/ IEC 23005-3). p 104

35. ITU-R (2000) Subjective assessment of stereoscopic television pictures (Rec. ITU-R BT.1438). ITU-R

36. ITU-T (1998) Subjective audiovisual quality assessment methods for multimedia applications (ITU-T Rec. P.911). 46

37. Jennings JR, Van Der Molen MW, Van Der Veen FM, Debski KB (2002) Influence of preparatory schema on the speed of responses to spatially compatible and incompatible stimuli. Psychophysiology 39:496-504

38. John OP, Donahue EM, Kentle RL (1991) The "Big Five" inventory: versions 4a and 5b. University of California, Berkeley, Institute of Personality and Social Research, Berkeley

39. John OP, Naumann LP, Soto CJ (2008) Paradigm shift to the integrative big-five trait taxonomy: history, measurement, and conceptual issues. In: John OP, Robins RW, Pervin LA (eds) Handb. Personal. Theory Res. Guilford Press, New York, NY, USA, pp 114-158

40. John OP, Srivastava S (1999) the big-five trait taxonomy: history, measurement, and theoretical perspectives. In: Pervin LA, John OP (eds) Handb. Personal. Theory Res., Vol. 2. Guilford Press, New York, pp 102-138

41. Jumisko-Pyykkö S (2011) User-centered quality of experience and its evaluation methods for mobile television. Tampere University of Technology

42. Kim J, Lee C-G, Kim Y, Ryu J (2013) Construction of a haptic-enabled broadcasting system based on the MPEG-V standard. Signal Process Image Commun 28:151-161

43. Knoche HO, McCarthy JD, Sasse M a (2005) Can small be beautiful? assessing image resolution requirements for mobile TV. Multimed'05 Proc 13th Annu ACM Int Conf Multimed 829-838. doi:10. $1145 / 1101149.1101331$

44. Laarni J, Ravaja N, Saari T, Hartmann T (2004) Personality-related differences in subjective presence. In: Alcañiz M, Rey B (eds) Proc. seventh Annu. Int. Work. presence 2004. UPV, Valencia, pp 88-95

45. LaPiere RT (1934) Attitudes vs. actions. Soc Forces 13:230-237. doi:10.2307/2570339

46. Le Callet P, Möller S, Perkis A (2012) Qualinet White Paper on Definitions of Quality of Experience (2012). European Network on Quality of Experience in Multimedia Systems and Services (COST Action IC 1003), Lausanne, Switzerland, Version 1.1, June 3, 2012

47. Lee S, Kim GJ (2008) Effects of visual cues and sustained attention on spatial presence in virtual environments based on spatial and object distinction. Interact Comput 20:491-502

48. Lessiter J, Freeman J, Keogh E, Davidoff J (2001) A cross-media presence questionnaire: the ITC-sense of presence inventory. Presence Teleoperators Virtual Environ 10:282-297. doi:10.1162/ 105474601300343612

49. Lombard M, Ditton T (1997) At the heart of it all: the concept of presence. J Comput Commun 3:0. doi:10. 1111/j.1083-6101.1997.tb00072.x

50. Luque FP, Galloso I, Feijoo C et al (2014) Integration of multi-sensorial stimuli and multi-modal interaction in a hybrid 3DTV system. ACM Trans Multimed Comput Commun Appl (TOMCAPP), Spec Issue MulseMedia 10:16:1-16:22. doi: 10.1145/2617992

51. McGurk H, MacDonald J (1976) Hearing lips and seeing voices. Nature 264:746-748

52. McLeod S (2014) Attitudes and behavior. In: online. http://www.simplypsychology.org/attitudes.html. Accessed 24 Sep 2015

53. Murray CD, Fox J, Pettifer S (2007) Absorption, dissociation, locus of control and presence in virtual reality. Comput Hum Behav 23:1347-1354. doi:10.1016/j.chb.2004.12.010

54. Murray N, Qiao Y, Lee B et al (2013) Subjective evaluation of olfactory and visual media synchronization. Proc. 4th ACM Multimed. Syst. Conf. ACM, New York, pp 162-171

55. Nabi RL, Krcmar M (2004) Conceptualizing media enjoyment as attitude: implications for mass media effects research. Commun Theory 14:288-310. doi:10.1111/j.1468-2885.2004.tb00316.x 
56. Neisser U (1976) Cognition and reality: principles and implications of cognitive psychology. W. H. Freeman, New York

57. Novak T, Hoffman D, Yung Y (2000) Measuring the customer experience in online environments: a structural modeling approach. Mark Sci 19:22-44

58. Obrist M, Tuch AN, Hornbaek K (2014) Opportunities for odor: experiences with smell and implications for technology. Proc SIGCHI Conf Hum Factors Comput Syst 2843-2852. doi: 10.1145/2556288.2557008

59. Rainer B, Waltl M, Cheng E et al (2012) Investigating the impact of sensory effects on the Quality of Experience and emotional response in web videos. 2012 Fourth Int. Work. Qual. Multimed. Exp. IEEE, pp 278-283

60. Raney AA, Bryant J (2002) Moral judgment and crime drama: an integrated theory of enjoyment. J Commun 52:402-415. doi:10.1111/j.1460-2466.2002.tb02552.x

61. Riva G, Mantovani F, Capideville CS et al (2007) Affective interactions using virtual reality: the link between presence and emotions. Cyberpsychol Behav 10:45-56. doi:10.1089/cpb.2006.9993

62. Rock I, Victor J (1964) Vision and touch: an experimentally created conflict between the two senses. Science 143:594-596

63. Rose CL, Murphy LB, Byard L, Nikzad K (2002) The role of the Big Five personality factors in vigilance performance and workload. Eur J Personal 16:185-200. doi:10.1002/per.451

64. Royston JP (1989) Correcting the shapiro-wilk Wfor ties. J Stat Comput Simul 31:237-249. doi:10.1080/ 00949658908811146

65. Sacau A, Laarni J (2005) The impact of personality factors on the experience of spatial presence. Presence 143-151

66. Sacau A, Laarni J, Hartmann T (2008) Influence of individual factors on presence. Comput Hum Behav 24: 2255-2273. doi:10.1016/j.chb.2007.11.001

67. Sas C, O’Hare GMP (2003) Presence equation: an investigation into cognitive factors underlying presence. Presence Teleoperators Virtual Environ 12:523-537. doi:10.1162/105474603322761315

68. Scheier C, Nijhawan R, Shimojo S (1999) Sound alters visual temporal resolution. Invest Ophthalmol Vis Sci 40:4169

69. Schuemie MJ, van der Straaten P, Krijn M, van der Mast CAPG (2001) Research on presence in virtual reality: a survey. CyberPsychol Behav 4:183-201. doi:10.1089/109493101300117884

70. Shapiro SS, Wilk MB (1965) An analysis of variance test for normality (complete samples). Biometrika 52: 591-611

71. Sherry JL (2004) Flow and media enjoyment. Commun Theory 14:328-347. doi:10.1111/j.1468-2885. 2004.tb00318.x

72. Shimojo S, Shams L (2001) Sensory modalities are not separate modalities: plasticity and interactions. Curr Opin Neurobiol 11:505-509

73. Skalski P, Tamborini R, Shelton A et al (2010) Mapping the road to fun: natural video game controllers, presence, and game enjoyment. New Media Soc 13:224-242

74. Skalski P, Whitbred R (2010) Image versus sound: a comparison of formal feature effects on presence and video game enjoyment. PsychNology J 8:67-84

75. Slater MD (2003) Alienation, aggression, and sensation seeking as predictors of adolescent use of violent film, computer, and website content. J Commun 53:105-121. doi:10.1111/j.1460-2466.2003.tb03008.x

76. Slater M (2003) A note on presence terminology. Presence-Connect 1-5

77. Slater M (2009) Place illusion and plausibility can lead to realistic behaviour in immersive virtual environments. Philos Trans R Soc Lond B Biol Sci 364:3549-3557. doi:10.1098/rstb.2009.0138

78. Slater M, Steed A, McCarthy J, Maringelli F (1998) The influence of body movement on subjective presence in virtual environments. Hum Factors 40:469-477

79. Slater M, Wilbur S (1997) A framework for immersive virtual environments (FIVE): speculations on the role of presence in virtual environments. Presence Teleoperators Virtual Environ 6:603-616

80. Sowden PT, Davies IR, Roling P (2000) Perceptual learning of the detection of features in X-ray images: a functional role for improvements in adults' visual sensitivity? J Exp Psychol Hum Percept Perform 26:379_ 390

81. Sowden PT, Rose D, Davies IRL (2002) Perceptual learning of luminance contrast detection: specific for spatial frequency and retinal location but not orientation. Vis Res 42:1249-1258. doi:10.1016/S00426989(02)00019-6

82. StataCorp LP (2015) STATA 12 [Computer software]. Available online from http://www.stata.com/. Accessed 29 Jul 2015.

83. Steuer J (1992) Defining virtual reality: dimensions determining telepresence. J Commun 42:73-93. doi:10. 1111/j.1460-2466.1992.tb00812.x 
84. Suzuki Y, Onda Y, Katada S et al (2004) Effects of an eyeglass-free 3-D display on the human visual system. Jpn J Ophthalmol 48:1-6. doi:10.1007/s10384-003-0001-7

85. Sylaiou S, Mania K, Karoulis A, White M (2010) Exploring the relationship between presence and enjoyment in a virtual museum. Int J Hum Comput Stud 68:243-253

86. Takatalo J, Nyman G, Laaksonen L (2008) Components of human experience in virtual environments. Comput Hum Behav 24:1-15. doi:10.1016/j.chb.2006.11.003

87. Tamborini R, Bowman ND, Eden A et al (2010) Defining media enjoyment as the satisfaction of intrinsic needs. J Commun 60:758-777. doi:10.1111/j.1460-2466.2010.01513.x

88. Ukai K, Howarth PA (2008) Visual fatigue caused by viewing stereoscopic motion images: background, theories, and observations. Displays 29:106-116. doi:10.1016/j.displa.2007.09.004

89. Usoh M, Catena E, Arman S, Slater M (2000) Using presence questionnaires in reality. Presence Teleoperators Virtual Environ 9:497-503. doi:10.1162/105474600566989

90. Västfjäll D (2003) The subjective sense of presence, emotion recognition, and experienced emotions in auditory virtual environments. Cyberpsychol Behav 6:181-188. doi:10.1089/109493103321640374

91. Visser P, Bizer G, Krosnick J (2006) Exploring the latent structure of strength-related attitude attributes. Adv Exp Soc Psychol. doi:10.1016/S0065-2601(06)38001-X

92. Vorderer P, Klimmt C, Ritterfeld U (2004) Enjoyment: at the heart of media entertainment. Commun Theory 14:388-408. doi:10.1111/j.1468-2885.2004.tb00321.x

93. Waltl M, Rainer B, Timmerer C, Hellwagner H (2013) An end-to-end tool chain for sensory experience based on MPEG-V. Signal Process Image Commun 28:136-150

94. Waltl M, Timmerer C, Hellwagner H (2010) Improving the Quality of multimedia Experience through sensory effects. Qual Multimed Exp (QoMEX), 2010 Second Int Work 124-129. doi:10.1109/QOMEX. 2010.5517704

95. Waltl M, Timmerer C, Hellwagner H (2010) Increasing the user experience of multimedia presentations with sensory effects. Image Anal. Multimed. Interact. Serv. (WIAMIS), 2010 11th Int. Work. IEEE, Desenzano del Garda, pp 1-4

96. Wechsung I, Schulz M, Engelbrecht K-P et al (2011) All users are (not) equal - the influence of user characteristics on perceived quality, modality choice and performance. In: Delgado RL-C, Kobayashi T (eds) Proc. Paralinguistic Inf. its Integr. Spok. Dialogue Syst. Work. Springer, New York, NY, pp 175-186

97. Weibel D, Wissmath B, Mast FW (2010) Immersion in mediated environments: the role of personality traits. Cyberpsychol Behav Soc Netw 13:251-256

98. Welch RB, Warren DH (1980) Immediate perceptual response to intersensory discrepancy. Psychol Bull 88: 638-667

99. Werner S, Thies B (2000) Is "change blindness" attenuated by domain-specific expertise? An expertnovices comparison of change detection in football images. Vis Cogn 7:163-173. doi:10.1080/ 135062800394748

100. Willander J, Larsson M (2006) Smell your way back to childhood: autobiographical odor memory. Psychon Bull Rev 13:240-244. doi:10.3758/BF03193837

101. Wirth W, Hartmann T, Böcking S et al (2007) A process model of the formation of spatial presence experiences. Media Psychology 9:493-525. doi:10.1080/15213260701283079

102. Witmer BG, Singer MJ (1998) Measuring presence in virtual environments: a presence questionnaire. Presence Teleoperators Virtual Environ 7:225-240. doi:10.1162/105474698565686

103. Wrzesniewski A, McCauley C, Rozin P (1999) Odor and affect: individual differences in the impact of odor on liking for places, things and people. Chem Senses 24:713-721. doi:10.1093/chemse/24.6.713

104. Yoon K (2013) End-to-end framework for 4-D broadcasting based on MPEG-V standard. Signal Process Image Commun 28:127-135

105. Zillmann D, Vorderer P (2000) Media entertainment: the psychology of its appeal. Lawrence Erlbaum Associates, Mahwah 


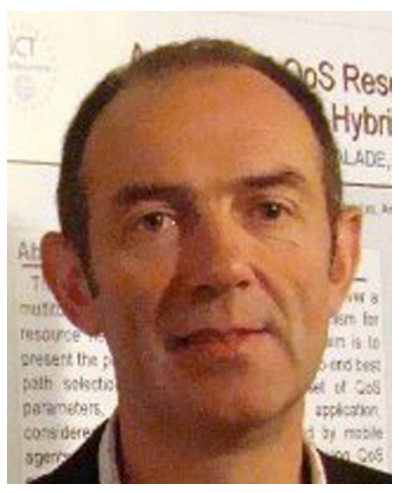

Claudio Feijóo is full Professor at UPM and at IE Business School, $\mathrm{PhD}$ in Telecommunications Engineering and an MSc in Economics, has been involved in numerous research, development and consulting projects in Europe, Asia, Latin America and North of Africa. He spent two years at the IPTS (EC) working on the future prospects of mobile content and applications. His research focuses on the future socio-economic impact of emerging information society technologies.

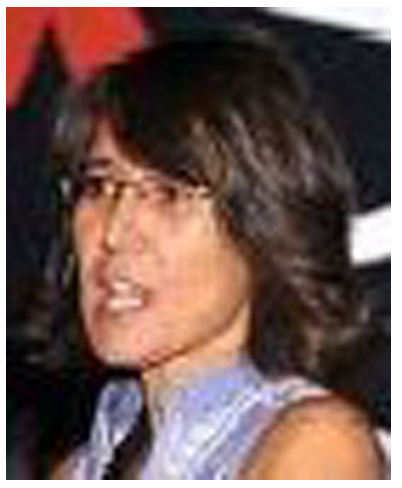

Prof. Asunción Santamaría is PhD in Telecommunications Engineering (PhD Special Award 1993/1994) and professor at the UPM Telecommunications School since 1994. She has participated in more than 60 R\&D projects (leading 30 of them), several of them belonging to the European Commission ESPRIT and ICT programs and to the European Space Agency. She is author or co-author of more than 25 scientific papers and books and more than 45 conference papers on wireless networks and ICT-based systems for energy efficiency. She is an IEEE Communications Society Member and has been member of Technical Reviewers Staff of IEEE and ASTED journals and conferences and member of Technical Reviewers Committee of Spanish National R\&D Programs. She has been the director of CeDInt-UPM since 2005. 